\title{
Untangling the Mistral and seasonal atmospheric forcing driving deep convection in the Gulf of Lion: 2012-2013
}

\author{
Douglas Keller Jr. ${ }^{1}$, Yonatan Givon ${ }^{2}$, Romain Pennel ${ }^{1}$, Shira Raveh-Rubin ${ }^{2}$, and Philippe Drobinski ${ }^{1}$ \\ ${ }^{1}$ LMD/IPSL, École Polytechnique, Institut Polytechnique de Paris, ENS, PSL Research University, Sorbonne Université, \\ CNRS, Palaiseau, France \\ ${ }^{2}$ Department of Earth and Planetary Sciences, Weizmann Institute of Science, Rehovot, Israel
}

Correspondence: Douglas Keller Jr. (dg.kllr.jr@gmail.com)

\begin{abstract}
Deep convection in the Gulf of Lion is believed to be primarily driven by the Mistral winds. However, our findings show that the seasonal atmospheric change provides roughly $2 / 3$ of the buoyancy loss required for deep convection to occur, for the 2012 to 2013 year, with the Mistral supplying the final 1/3. Two NEMOMED12 ocean simulations of the Mediterranean Sea were run for the Aug. 1st, 2012 to July 31st, 2013 year, forced with two sets of atmospheric forcing data from a RegIPSL coupled run within the Med-CORDEX framework. One set of atmospheric forcing data was left unmodified, while the other was filtered to remove the signal of the Mistral. The Control simulation featured deep convection, while the Seasonal did not. A simple model was derived, relating the anomaly scale forcing (the difference between the Control and Seasonal runs) and the seasonal scale forcing to the ocean response through the Stratification Index. This simple model revealed that the Mistral's effect on buoyancy loss depends more on its strength rather than its frequency or duration. The simple model also revealed that the seasonal cycle of the Stratification Index is equal to the net surface heat flux over the course of the year, with the stratification maximum and minimum occurring roughly at the fall and spring equinoxes.
\end{abstract}

\section{Introduction}

Deep convection, also known as open-ocean convection, is an important ocean circulation process that typically occurs in the high latitude regions (Marshall and Schott, 1999). Localized events are triggered by the reduction of the stable density gradient through sea surface layer buoyancy loss. One such area of deep convection is the Gulf of Lion (GOL) in the Mediterranean Sea. The deep convection events that occur in this region aid the general thermohaline circulation of the Mediterranean Sea by forming the Western Mediterranean Dense Water (WDMW) (Robinson et al., 2001). After its formation, this dense water spreads out along the northwestern basin, among the deeper layers of the Med. Sea (MEDOC, 1970), with some transported along the northern boundary current towards the Balearic Sea (Send and Testor, 2017), and some transported to the south within eddies (Beuvier et al., 2012; Testor and Gascard, 2003) into the southern Algerian Basin and towards the Strait of Gibraltar (Béranger et al., 2009), completing the cyclonic circulation pattern of the sea. The water column mixing that occurs during 
a deep convection event also brings oxygenated water down from the oxygen-rich sea surface layer and injects sea-bottom nutrients upwards towards the surface (Coppola et al., 2017; Severin et al., 2017), resulting in increased phytoplankton blooms in the following season (Severin et al., 2017).

Significant deep convection events occur every few years in the Gulf of Lion (GOL) (Somot et al., 2016; Houpert et al., 2016; Marshall and Schott, 1999; Mertens and Schott, 1998), driven by the Mistral and Tramontane winds. These sister northerly flows bring cool, continental air through the Rhône Valley (Mistral) and the Aude Valley (Tramontane) leading to large heat transfer events with the warmer ocean surface (Drobinski et al., 2017; Flamant, 2003). These cooling and evaporation events destabilize the water column in the GOL, and are widely accepted to be the primary source of buoyancy loss leading to deep convection (Lebeaupin-Brossier et al., 2017; Houpert et al., 2016; L'Hévéder et al., 2012; Lebeaupin-Brossier et al., 2012; Herrmann et al., 2010; Lebeaupin-Brossier and Drobinski, 2009; Noh et al., 2003; Marshall and Schott, 1999; Mertens and Schott, 1998; Madec et al., 1996; Schott et al., 1996; Madec et al., 1991b,a; Gascard, 1978).

Here, we investigated the Mistral's role in deep convection in the GOL and found that the seasonal atmospheric cycle has just as much importance in terms of buoyancy loss as the integrated effect of successive Mistral events (as the Mistral and Tramontane winds are sister winds, we will refer to them jointly as "Mistral" winds). This was determined by running two NEMO ocean simulations of the Med. Sea from Aug. 1st, 2012 to July 31st, 2013. One simulation was forced by unmodified atmospheric forcing data, while the other was forced by a filtered atmospheric dataset with the signal of the Mistral removed from the forcing. Thus, the ocean response due to the Mistral events could be separated and examined, revealing the effects of seasonal atmospheric change alone. A multitude of observational data was collected during this year in the framework of the HYdrological cycle in the Mediterranean EXperiment (HyMeX) (Estournel et al., 2016b; Drobinski et al., 2014), which provided a solid base of observations to validate the ocean model results.

In particular, our findings quantify:

- the separated and combined effect of the Mistral and seasonal atmospheric cycle on deep convection,

- the dominant attribute of the Mistral causing buoyancy loss,

- the source of the buoyancy loss due to the seasonal atmospheric cycle.

There are three distinct sections of the deep convection cycle: the preconditioning phase in the fall, the main, large overturning phase in the winter and early spring (when deep convection occurs), and the restratification/spreading phase during the proceeding summer (MEDOC, 1970; Group, 1998). The focus of study is on the preconditioning and overturning phase where the Mistral is stronger and more frequent (Givon et al., 2021) and therefore plays a larger role in the deep convection cycle.

The model used and the methodology is described in the methods section (Sec. 2). Model results and validation are presented in the results and discussion section (Sec. 3). Patterns observed in the model results lead to the development of simple model that describes the Mistral's and seasonal cycle's effect. This simple model is presented in the latter half of the same section. Our concluding remarks are presented in the conclusions section (Sec. 4). 


\section{Methodology}

In our study we used the NEMO ocean model to run two ocean simulations forced by unmodified and modified atmospheric forcing data from a coupled WRF/ORCHIDEE simulation. Information on the Mistral events, used later when developing the simple model in Sec. 3, was extracted from the unmodified atmospheric forcing data and from ERA Interim Reanalysis data. The main metric used in this article to examine the model results and relate them to deep convection is the Stratification Index, $S I$. Each of these components are described below in their own subsection.

\subsection{NEMO}

The Nucleus for European Modelling of the Ocean (NEMO) ocean model (https://www.nemo-ocean.eu/) was used in bulk formula configuration to simulate the Gulf of Lion region with two distinct simulations, both performed from Aug. 1st, 2012 to July 31st, 2013. In bulk formula configuration, sea surface fluxes are computed from parameterized formulas using atmospheric and oceanic measurable variables as inputs, such as temperature and wind velocity. The following parameterized formulas are used to calculate the latent heat flux, $Q_{E}$, the sensible heat flux, $Q_{H}$, the longwave radiation heat flux, $Q_{L W}$, and the surface shear stress, $\tau$ :

$$
\begin{aligned}
Q_{E} & =\rho_{0} \Lambda C_{E}\left(q_{z}-q_{0}\right)|\Delta \boldsymbol{u}| \\
Q_{H} & =\rho_{0} c_{p} C_{H}\left(\theta_{z}-S S T\right)|\Delta \boldsymbol{u}| \\
Q_{L W} & =Q_{L W, a}-\epsilon \sigma S S T_{K}^{4} \\
\tau & =\rho_{0} C_{D} \Delta \boldsymbol{u}|\Delta \boldsymbol{u}|
\end{aligned}
$$

where $z$ is the height above the sea surface the atmospheric variables are provided at, with the naught values $(0)$ representing the values at the sea surface. $\boldsymbol{u}$ is the horizontal wind vector, with $\Delta \boldsymbol{u}=\boldsymbol{u}_{z}-\boldsymbol{u}_{0}$, the difference between the wind velocity and sea surface current (assuming a no-slip condition at the ocean surface). $q$ and $\theta$ are the specific humidity and potential temperature of air, respectively. $\Lambda$ and $c_{p}$ are the latent heat of evaporation and the specific heat of water, respectively. $\rho_{0}$ is the air density at the sea surface. $S S T$ is the sea surface temperature, with $S S T_{K}$ as the sea surface absolute temperature. $\epsilon$ is the sea surface emissivity, $\sigma$ is the Stefan-Boltzmann constant, and $Q_{L W, a}$ is the atmospheric longwave radiation. $C_{E}, C_{H}$, and $C_{D}$ are the coefficients of latent heat, sensible heat, and drag, respectively, and are defined in Large and Yeager (2004, 2008).

The net downward heat flux, $Q_{n e t}$, is described by the summation of the terms in the following equation (neglecting snowfall; Large and Yeager (2004); Estournel et al. (2016b)):

$Q_{n e t}=Q_{S W}+Q_{L W}+Q_{H}+Q_{E}$

where $Q_{S W}$ is the downward shortwave radiation.

The NEMO model was run in the NEMOMED12 configuration using NEMO v3.6. The domain shown in Fig. 1 (b); it covers the Mediterranean Sea and a buffer zone representing the exchanges with the Atlantic Ocean. This configuration features a 

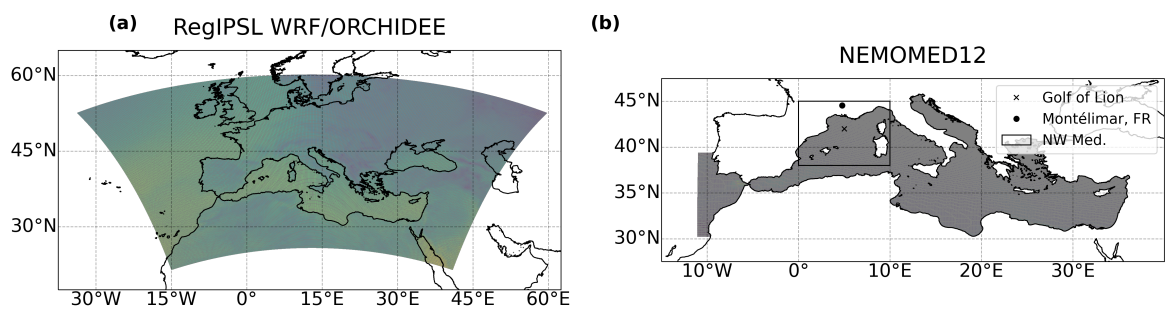

Figure 1. The domains of both the WRF domain from the RegIPSL coupled WRF/ORCHIDEE simulation within the Med-CORDEX framework, (a), and the NEMOMED12 configuration domain for, (b). The region of interest, the NW Med., is outlined by the box. This region is later used in Fig. 6 . The location used to study the temporal development of deep convection in the Gulf of Lion at $42^{\circ} \mathrm{N} 5^{\circ} \mathrm{E}$, and the other location, used in conjunction with aforementioned point to determine Mistral events, is Montélimar, FR marked by the at $44.56^{\circ} \mathrm{N}$ $4.75^{\circ} \mathrm{E}$.

horizontal resolution of $1 / 12^{\circ}$ (roughly $7 \mathrm{~km}$ ) and 75 vertical levels (with a variable vertical resolution from $1 \mathrm{~m}$ at the surface to $135 \mathrm{~m}$ at the bottom). The 3-D temperature and salinity fields are restored towards the ORAS4 global ocean reanalysis (Balmaseda et al., 2013) in the buffer zone. The conservation of volume in the buffer zone is achieved through strong damping of the sea surface height (SSH) towards the ORAS4 reanalysis. The Black Sea, runoff of 33 major rivers, and coastal runoff is represented by climatological data input from Ludwig et al. (2009). A deeper explanation of the configuration and boundary conditions is given by the works Waldman et al. (2018); Hamon et al. (2016); Beuvier et al. (2012); Lebeaupin-Brossier et al. (2011); Arsouze et al.. The initial conditions were provided by an ocean objective analysis by Estournel et al. (2016b).

\subsection{Atmospheric forcing}

The atmospheric forcing used in the simulations were the outputs of RegIPSL, the regional climate model of IPSL (Guion et al., 2021), which used the coupling of the Weather Research and Forecasting Model (WRF) (Skamarock et al., 2008) and the ORCHIDEE Land Surface Model (Krinner et al., 2005). The run was a hind-cast simulation (ERA interim downscaling), performed at $20 \mathrm{~km}$ resolution, spanning the period of 1979-2016, within the Med-CORDEX framework (Ruti et al., 2016). The $u$ and $v$ components, specific humidity, potential temperature, shortwave and longwave downward radiation, precipitation, and snowfall were all used to force the ocean simulations.

For the "Control" simulation, the forcing were used as is. For the "Seasonal" simulation, the $u$ and $v$ wind components, specific humidity, and potential temperature were filtered, see Fig. 2, over the entire domain shown in Fig. 1 (a). These variables were chosen as they are the primary variables that affect the surface flux calculations in the bulk formulae (Eq. set (1)). The variables relating to radiation and precipitation fluxes were left unchanged. The filtering removes the short term, anomaly scale forcing from the forcing dataset (the phenomena with under a month timescale), effectively removing the Mistral's influence on the ocean response. This creates two separate forcing datasets, one with the anomaly scale forcing included, one with just the seasonal scale forcing (hence the designation of Control and Seasonal). 
The filtering process was performed by a moving window average:

$$
\chi_{i}=\frac{1}{i+N+1} \sum_{j=0}^{i+N} x_{j}
$$

where $\chi_{i}$ is the averaged (filtered) value at index $i$ of a time series of variable $x$ with length $n$, where $i=0 \rightarrow n$. The window size is equal to $2 N+1$, which, in this case, is equal to 31 days. The ends have a reduced window size for averaging, and thus show edge effects. The edge effects did not affect the forcing used for the NEMO simulations, as they were before and after the ocean simulation dates, as two, full year atmospheric forcing data were used for the simulations.

The moving window average was applied to each time point per day over a 31 day window (i.e. for 3 hourly data, the time series is split into 8 separate series, one for each timestamp per day - 00:00, 03:00, 06:00, etc. - then averaged with a moving window before being recombined). This was done to retain intra-day variability yet smooth the intra-monthly patterns, as the diurnal cycle has been shown to retard destratification by temporarily reforming a stratified layer at the sea surface during slight daytime warming. This diurnal restratification has to be overcome first before additional destratification of the water column can continue during the next day (Lebeaupin-Brossier et al., 2012, 2011) and is shorter than the typical Mistral event length of about 5.69 days (Table 1).

The result of the filtering is shown in Fig. 2. Temperature and specific humidity were filtered as is, while the wind speed, calculated from the $u$ and $v$ components, was filtered while preserving the wind direction. Due to the slow movement of intermediate and dense water, which is at about a year scale for newly formed WMDW to move into the southern Algerian Basin (Beuvier et al., 2012) and on the order of decades for total circulation (Millot and Taupier-Letage, 2005), we assume the processes outside the NW Med. subdomain in Fig. 1 (b), that are affected by the filtering have a negligible impact on the GOL processes on the preconditioning phase timescale.

\subsection{Mistral events}

Mistral events will be used for developing the simple model in the results and discussion section (Sec. 3.3), for their role in driving buoyancy loss at the ocean surface. Events were determined from the WRF/ORCHIDEE dataset, in combination with the ERA Interim Reanalysis dataset (Dee et al., 2011). Two main criteria were used to define a Mistral event:

1. Northerly flow with a stream-wise flow direction $\pm 45^{\circ}$ about the south cardinal direction, above $2 \mathrm{~m} / \mathrm{s}$ at two locations simultaneously: at Montélimar, France $\left(45.5569^{\circ} \mathrm{N}, 4.7495^{\circ} \mathrm{E}\right)$ and in the Gulf of Lion $\left(42.6662^{\circ} \mathrm{N}, 4.4372^{\circ} \mathrm{E}\right)$.

2. The presence of a Genoa Low, defined as a closed sea level pressure contour around a minimum in the field, using 0.5 $\mathrm{hPa}$ intervals, anywhere in the box defined by the latitudes 38 and $44^{\circ} \mathrm{N}$ and longitudes 4 and $14^{\circ} \mathrm{E}$ (a slightly different domain than that of Givon et al. (2021)).

The events during the preconditioning period, Aug. 30th, 2012 to Feb. 21st, 2013, were then manually checked and edited to remove single day gaps to better represent the data according to a visual inspection of the atmospheric forcing data. For $k$ 
https://doi.org/10.5194/os-2021-72

Preprint. Discussion started: 9 August 2021
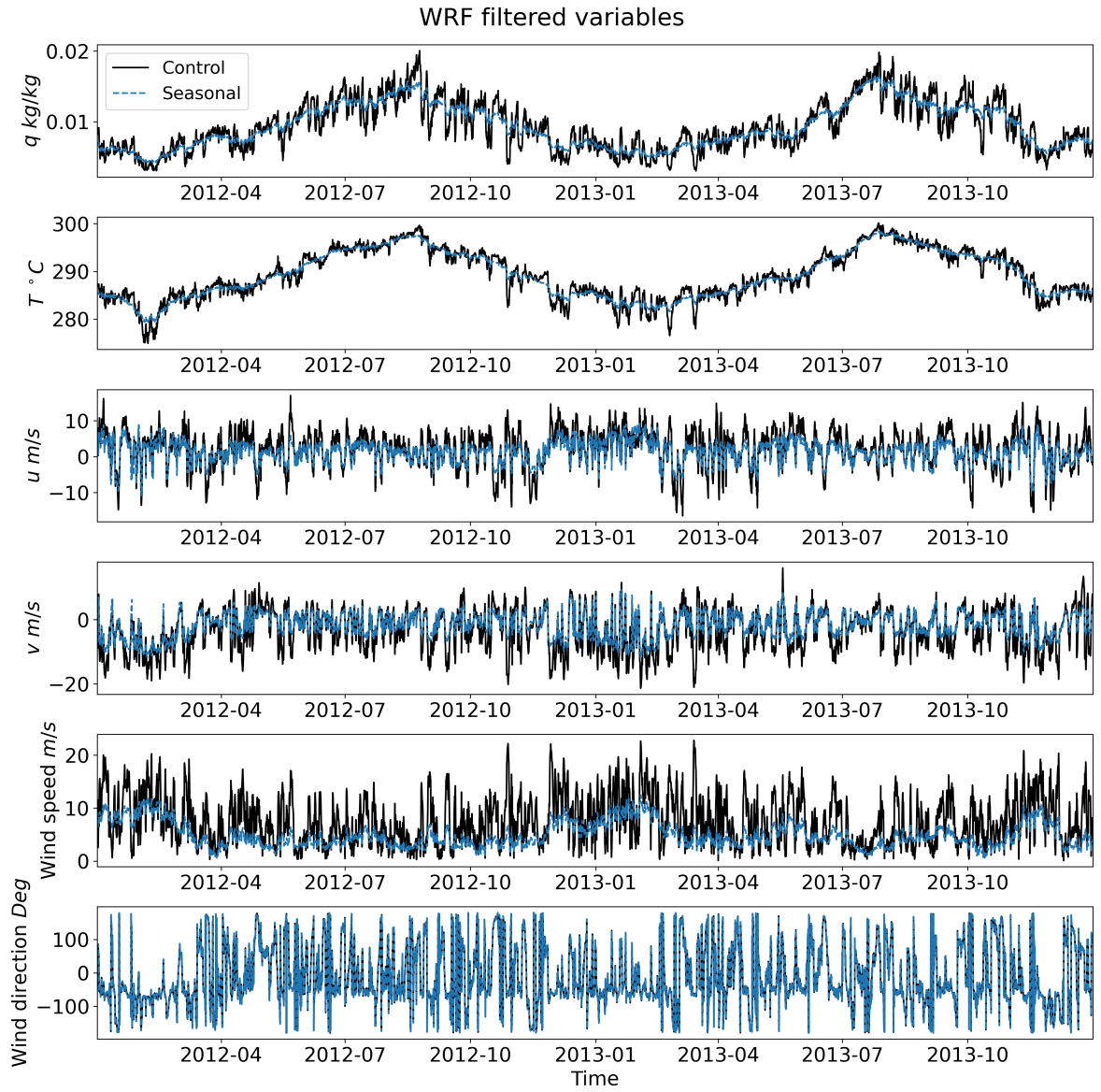

Figure 2. An illustration of filtering (averaging) process described by Eq. (3). Here the variables $q$, $T$, $u$, and $v$ are shown for both the unfiltered (Control) and filtered (Seasonal) datasets at the nearest grid point to $42^{\circ} \mathrm{N} 5^{\circ}$ E. Note how the peaks of the time series are removed except for in the wind direction sub-plot.

Mistral events, each event's duration, $\Delta t_{k}$, and period from the beginning of the event to the next event, $\Delta \tau_{k}$, was determined and is provided in Table 1 for the entire ocean simulation period (for further analysis into the selection of this criteria, see Givon et al. (2021)).

\subsection{Stratification Index}

A useful metric to quantify the vertical stratification of a column of water is the Stratification Index, SI (Léger et al. (2016); Somot et al. (2016); Somot (2005); sometimes called the "convection resistance"). It's derived from the non-penetrative growth of the Mixed Layer Depth (MLD; i.e. without entrainment; Turner (1973)), which has been shown to be an accurate approximation for open ocean convection (Marshall and Schott, 1999): 
https://doi.org/10.5194/os-2021-72

Preprint. Discussion started: 9 August 2021

(c) Author(s) 2021. CC BY 4.0 License.

Table 1. The start date of, duration of, $\Delta t_{k}$, and period between each event, $\Delta \tau_{k}$, for each Mistral event, $k$, for the entire NEMO simulation period of Aug. 1st, 2012 to July 31st, 2013. Superscripts $d$ and $a$ denote events used as ideal cases for calculating $\alpha_{d}$ and $\alpha_{a}$, respectively, in Sec. 3.5 and App. A2.1 and A2.2.

\begin{tabular}{|c|c|c|c|c|c|}
\hline Start Date & $\Delta t_{k}$ days & $\Delta \tau_{k}$ days & Start Date & $\Delta t_{k}$ days & $\Delta \tau_{k}$ days \\
\hline 2012-08-03 & 1 & 3 & $2012-12-26$ & 5 & 7 \\
\hline 2012-08-06 & 1 & 2 & 2013-01-02 & 17 & 21 \\
\hline 2012-08-08 & 1 & 5 & 2013-01-23 & 6 & 10 \\
\hline 2012-08-13 & 1 & 12 & $2013-02-02^{d}$ & 15 & 18 \\
\hline $2012-08-25$ & 2 & 5 & 2013-02-20 & 7 & 10 \\
\hline $2012-08-30^{d, a}$ & 8 & 13 & 2013-03-02 & 1 & 11 \\
\hline $2012-09-12^{d, a}$ & 4 & 7 & 2013-03-13 & 3 & 7 \\
\hline $2012-09-19^{d, a}$ & 2 & 9 & 2013-03-20 & 1 & 6 \\
\hline $2012-09-28^{d, a}$ & 5 & 14 & $2013-03-26$ & 1 & 5 \\
\hline $2012-10-12^{d, a}$ & 4 & 15 & 2013-03-31 & 1 & 6 \\
\hline $2012-10-27^{d}$ & 5 & 15 & 2013-04-06 & 2 & 13 \\
\hline $2012-11-11^{d, a}$ & 3 & 8 & 2013-04-19 & 4 & 8 \\
\hline 2012-11-19 & 2 & 8 & 2013-04-27 & 1 & 25 \\
\hline $2012-11-27^{d}$ & 6 & 11 & $2013-05-22$ & 2 & 10 \\
\hline $2012-12-08^{d}$ & 4 & 9 & 2013-06-01 & 2 & 23 \\
\hline $2012-12-17^{d}$ & 3 & 4 & 2013-06-24 & 1 & 4 \\
\hline $2012-12-21$ & 2 & 5 & 2013-06-28 & 1 & 41 \\
\hline
\end{tabular}

The average values for Mistral events from 2012-08-30 to 2013-02-16 are: $\overline{\Delta t}=5.69$ days and $\overline{\Delta \tau}=10.88$ days. The standard deviations for the same time frame are: $\sigma_{\Delta t}=4.22$ days and $\sigma_{\Delta \tau}=4.59$ days.

$$
\frac{\partial z}{\partial t}=\frac{B(t)}{N^{2}(z) z}
$$

where $N^{2}$ is the Brunt-Väisälä frequency, $z$ is the vertical coordinate along the water column, $\frac{\partial z}{\partial t}$ is the growth of the mixed layer depth, and $B$ is the potential buoyancy loss the water column can endure before removing stratification (in units of $\mathrm{m}^{2} / \mathrm{s}^{3}$ ). Separating by variables and integrating results in the equation for $S I$ :

$145 S I=\int_{0}^{D} N^{2} z d z$

where $D$ is the depth of water column. If $N^{2}$ is assumed to be constant throughout the water column, the integral simplifies to: 
$S I=\frac{D^{2}}{2} N^{2}$

$S I$ provides a 0 dimensional index to track stratification and can be easily related to the buoyancy loss experienced by the water column due to the atmosphere. Because of this, in this article $S I$ will be used as the diagnostic to track the atmosphere's impact on the stratification of the GOL waters.

\section{Results and Discussion}

The results are presented in two parts: model validation against observational data and the model results of the deep convection cycle presented from the center of convection, roughly at $42^{\circ} \mathrm{N} 5^{\circ} \mathrm{E}$ for the 2012 to 2013 winter.

\subsection{Model validation}

To validate the model results, data from the HyMeX (https://www.hymex.org/) database was compared to the NEMO control simulation. Sea surface temperature (SST) data from Météo-France's Azur and Lion buoy were compared with the Control simulation SST of the nearest grid point in NEMOMED12. Figure 3 shows the comparison. The Azur buoy data was missing SST measurements from Jan. 19th, 2013 to July 10th, 2013, but where the data is available, NEMO corresponds well to the observations. The same is true for the Lion buoy data, which had measurements for the entire time covered by the simulations. This comes as no surprise, as the NEMOMED12 simulations' SST is restored to the observational dataset of Estournel et al. (2016b). However, this also means that the calculated surface sensible heat fluxes should be fairly accurate, as both the sensible heat flux and latent heat flux calculations depend on the SST (Eq. (1)).

Additionally, the Control simulation density and potential temperature profiles were compared to Conductivity-TemperatureDepth (CTD) measurements also procured from the HyMeX database. The CTD measurements were collected during the HyMeX Special Observation Period 2 (Taupier-Letage Isabelle, 2013; Estournel et al., 2016a; Drobinski et al., 2014) mission. The CTD profiles collected at approximately the same time and location were averaged together to adjust for small variances and gaps in the data. The averaged profiles and their standard deviations are visualized in Fig. 4 and Fig. 5.

Like with the SST comparisons, the profiles from the nearest grid point in the Control simulation domain were used for the CTD comparisons. The Root Mean Square Error (RMSE) and bias (calculated as the difference between the model values and the observation values) for each of the averaged CTD profiles and corresponding Control simulation profiles was calculated and is presented in Table 2. Overall, the Control simulation and CTD profiles are decently well correlated but not perfect, with low RMSE and bias for both density and potential temperature. The density profiles have an average RMSE less than the average RMSE for the potential temperature profiles: $0.025 \mathrm{~kg} / \mathrm{m}^{3}$ and $0.094{ }^{\circ} \mathrm{C}$, respectively.

Temperature differences on the order of $10^{-2}{ }^{\circ} \mathrm{C}$ are potentially all that is required to sustain an ocean convective cycle (Marshall and Schott, 1999) and density differences for the same order of magnitude, $10^{-2} \mathrm{~kg} / \mathrm{m}^{3}$, are used to separate newly formed dense water during deep convection (Houpert et al., 2016; Somot et al., 2016; Beuvier et al., 2012). This means 


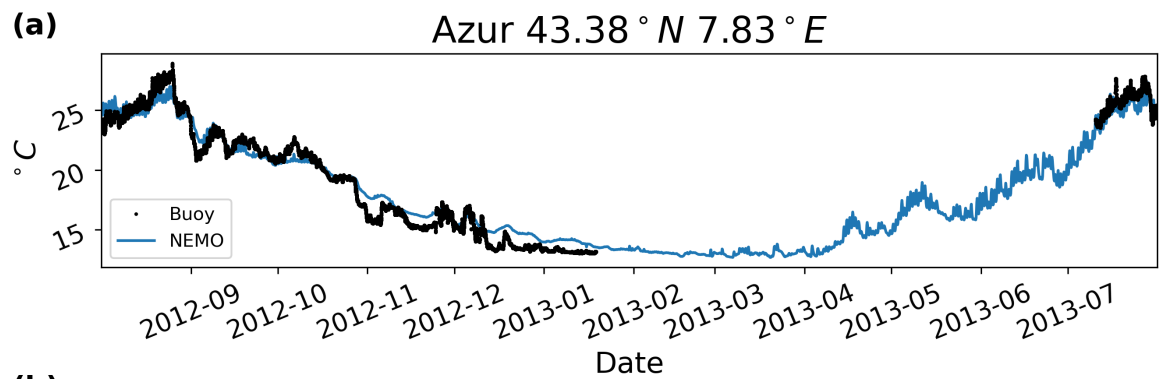

(b)

Lion $42.06^{\circ} \mathrm{N} 4.64^{\circ} \mathrm{E}$

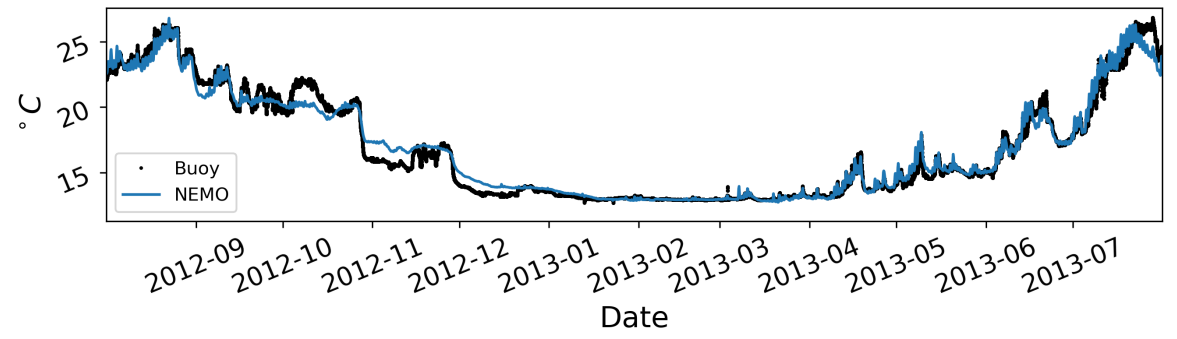

Figure 3. SST comparison between the NEMO Control run and the Azur, (a), and Lion, (b), buoy SST datasets. Where the data is available, the model results match the buoy data fairly well.

the model results should be studied with a critical eye, as they may not be fully representative of the true ocean response. Additionally, meanders around $40 \mathrm{~km}$ in wavelength form due to baroclinic instability along edge of the convection patch (Gascard, 1978). This could mean the deviations from observations are due to out-of-phase meanders around the convective patch region in the model relative to actuality. Regardless, we believe the simulations are accurate enough to provide interesting results for the transient and regional scale response of the GOL, which covers the main interest of our study.

\subsection{Stratification Index and Mixed Layer Depth}

Figure 6 shows the $S I$ calculated over the GOL for both the simulations: row (a) for the Control and row (b) for the Seasonal. An important distinction between the two results is deep convection is present in the Control simulation but not the Seasonal. This is more clearly seen in Fig. 7 (c) (closest NEMOMED12 grid point to $42^{\circ} \mathrm{N}, 5^{\circ} \mathrm{E}$ ), as the Control simulation MLD reaches the sea floor on Feb. 13, 2013, while the Seasonal MLD remains close to the sea surface. This confirms that atmospheric forcing with timescales less than a month, e.g. the Mistral winds, provide a significant amount of buoyancy loss, as without them deep convection fails to occur. There is, however, still significant loss of stratification at the location of the GOL gyre in the Seasonal simulation, which is visible in row (b) of Fig. 6 on the date of Feb. 13th, 2013. This spot of destratification is present, but less so, in the preceding and proceeding plots of the same row.

To investigate the time series ocean response in more detail, a spatially averaged time series of the $S I$ for both simulations was analyzed at the grid point nearest to $42^{\circ} \mathrm{N}, 5^{\circ}$ E. These coordinates were selected as it is the point with the most destrat- 
https://doi.org/10.5194/os-2021-72

Preprint. Discussion started: 9 August 2021

(c) Author(s) 2021. CC BY 4.0 License.
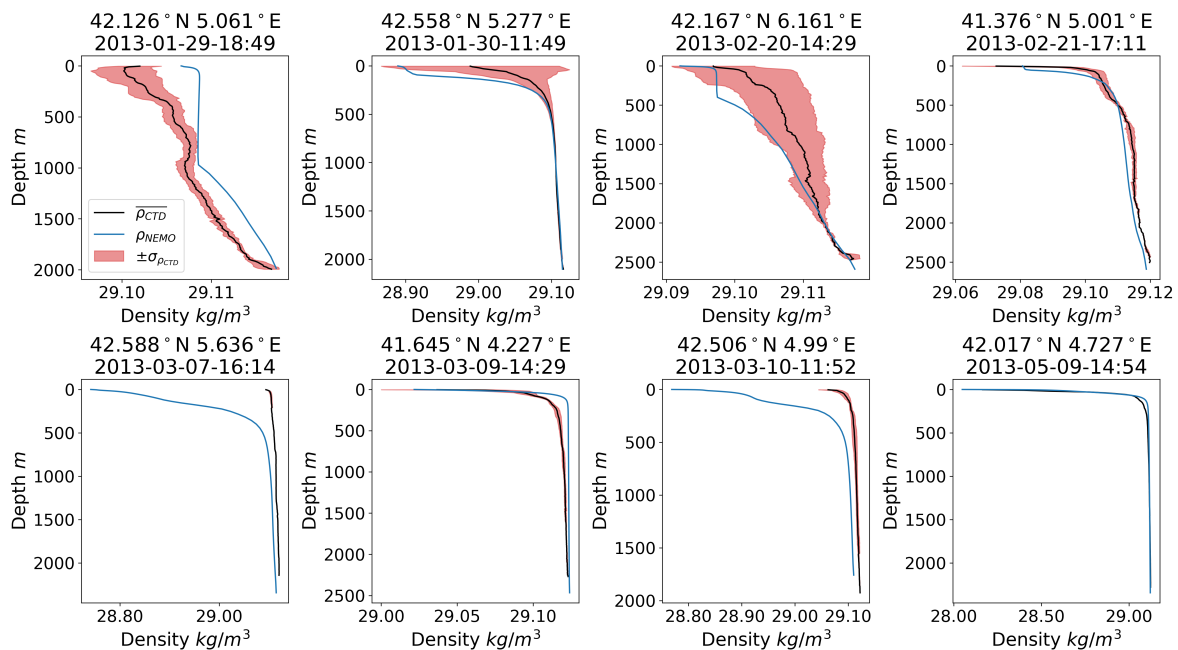

Figure 4. Comparison of CTD and NEMO Control simulation density profiles. The CTD profiles were averaged by combining multiple vertical profiles collected at the date and location into one profile. The standard deviation of this averaging, $\sigma_{\rho_{C T D}}$, is marked in red and is present for all plots, yet may be difficult to see for March 7th and May 9th.
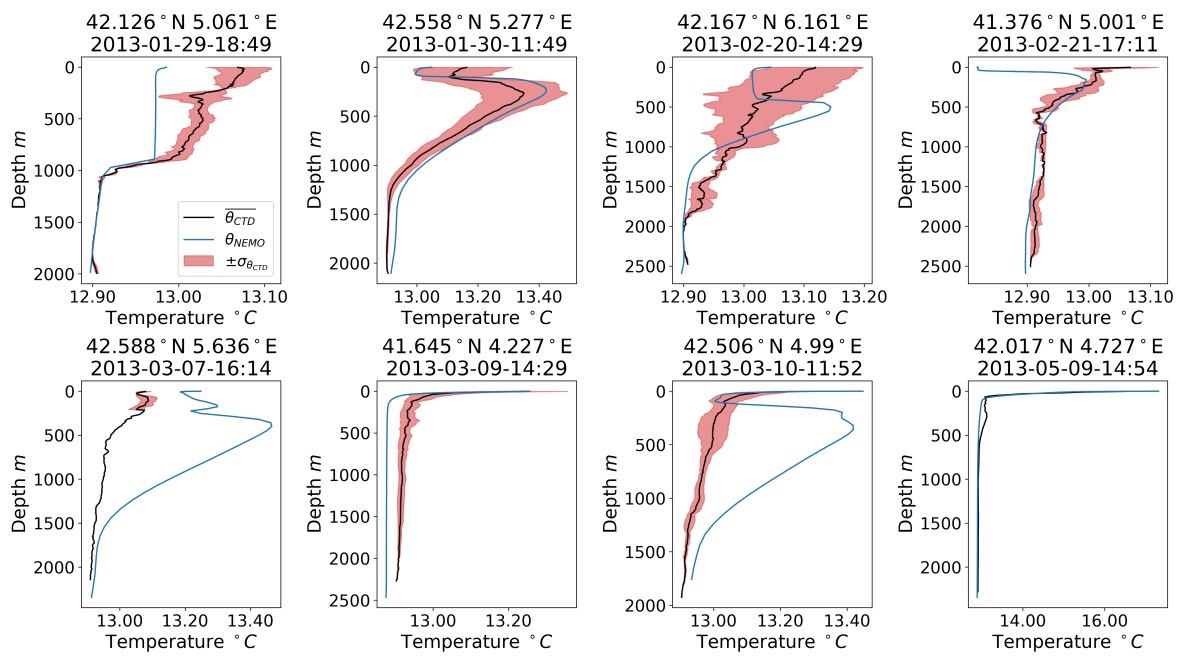

Figure 5. Same as Fig. 4 but for potential temperature.

ification in Fig. 6, and is the typical center of deep convection in the GOL (Marshall and Schott, 1999; MEDOC, 1970). The spatial averaging involved horizontally averaging the immediately adjacent grid points, such that 9 grid points in total were averaged, centered around $42^{\circ} \mathrm{N}, 5^{\circ} \mathrm{E}$. The Stratification Index from the Control simulation is given as the sum of $\delta S I+S I_{S}$, while the Stratification Index of the Seasonal simulation is given as $S I_{S}$. The difference between the two, $\delta S I$, should contain 
https://doi.org/10.5194/os-2021-72

Preprint. Discussion started: 9 August 2021

Table 2. RMSE and bias between the averaged observed CTD density and potential temperature profiles and the nearest NEMO Control grid point profiles, for the respective variables.

\begin{tabular}{lcccccc}
\hline Date & Lat. deg & Lon. $d e g$ & $\operatorname{RMSE}_{\rho} \mathrm{kg} / \mathrm{m}^{3}$ & $\mathrm{RMSE}_{\theta}{ }^{\circ} \mathrm{C}$ & $\operatorname{Bias}_{\rho} \mathrm{kg} / \mathrm{m}^{3}$ & $\operatorname{Bias}_{\theta}{ }^{\circ} \mathrm{C}$ \\
\hline 2013-01-29-18:49 & 42.126 & 5.061 & 0.004 & 0.041 & 0.0032 & -0.0265 \\
2013-01-30-11:49 & 42.558 & 5.277 & 0.030 & 0.055 & -0.0093 & 0.0348 \\
2013-02-20-14:29 & 42.167 & 6.161 & 0.004 & 0.050 & -0.0026 & -0.0059 \\
2013-02-21-17:11 & 41.376 & 5.001 & 0.003 & 0.033 & -0.0019 & -0.0120 \\
2013-03-07-16:14 & 42.588 & 5.636 & 0.077 & 0.233 & -0.0377 & 0.1751 \\
2013-03-09-14:29 & 41.645 & 4.227 & 0.005 & 0.043 & 0.0036 & -0.0414 \\
$2013-03-10-11: 52$ & 42.506 & 4.990 & 0.058 & 0.224 & -0.0320 & 0.1719 \\
$2013-05-09-14: 54$ & 42.017 & 4.727 & 0.018 & 0.077 & 0.0046 & -0.0367 \\
\hline
\end{tabular}

The average RMSE and bias for the density profiles was $0.025 \mathrm{~kg} / \mathrm{m}^{3}$ and $-0.009 \mathrm{~kg} / \mathrm{m}^{3}$, respectively. The average RMSE and bias for potential temperature was $0.094{ }^{\circ} \mathrm{C}$ and $0.032{ }^{\circ} \mathrm{C}$, respectively.

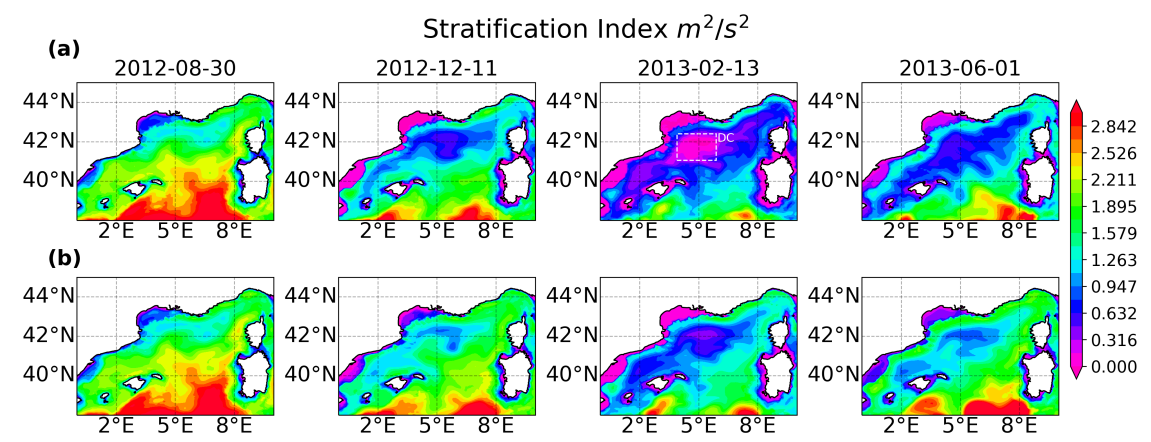

Figure 6. The Stratification Index across the Gulf of Lion (the area marked as NW Med. in Fig. 1 (b)) at different timestamps. Row (a) displays the values of $S I$ for the Control simulation and row (b) displays the values of $S I$ for the Seasonal simulation. The box denoted by $D C$ indicates the area of deep convection in the Gulf of Lion that was not seen in the Seasonal simulation.

the change in stratification due to shorter timescale atmospheric events, such as the Mistral, because of the filtering performed in Sec. 2.2. $\delta S I+S I_{S}, S I_{S}$, and $\delta S I$ are all shown in Fig. 7.

Both the Control and Seasonal runs start off with an $S I$ value of $1.57 \mathrm{~m}^{2} / \mathrm{s}^{2}$ (beginning of Fig. 7 (a)), then diverge at the first major Mistral event starting on August 30th, 2012. After diverging, the two runs remain diverged until the end of the simulation run time, ending with a difference of about $-0.22 \mathrm{~m}^{2} / \mathrm{s}^{2}$, which is seen in $\delta S I$ (shown in Fig. 7 (b)). As commented earlier, the most striking difference between the Control and Seasonal run is the occurrence of deep convection in the Control run, occurring when $\delta S I+S I_{S}$ is equal to 0 (signified also when the MLD reaches the sea floor), and the lack of deep convection in the Seasonal run, as $S I_{S}$ only reaches a minimum of $0.43 \mathrm{~m}^{2} / \mathrm{s}^{2}$. Additionally, if only the anomaly timescale atmospheric forcing is considered, hence $\delta S I$ is the only stratification change from the initial $1.57 \mathrm{~m}^{2} / \mathrm{s}^{2}$, the roughly $-0.6 \mathrm{~m}^{2} / \mathrm{s}^{2}$ of 

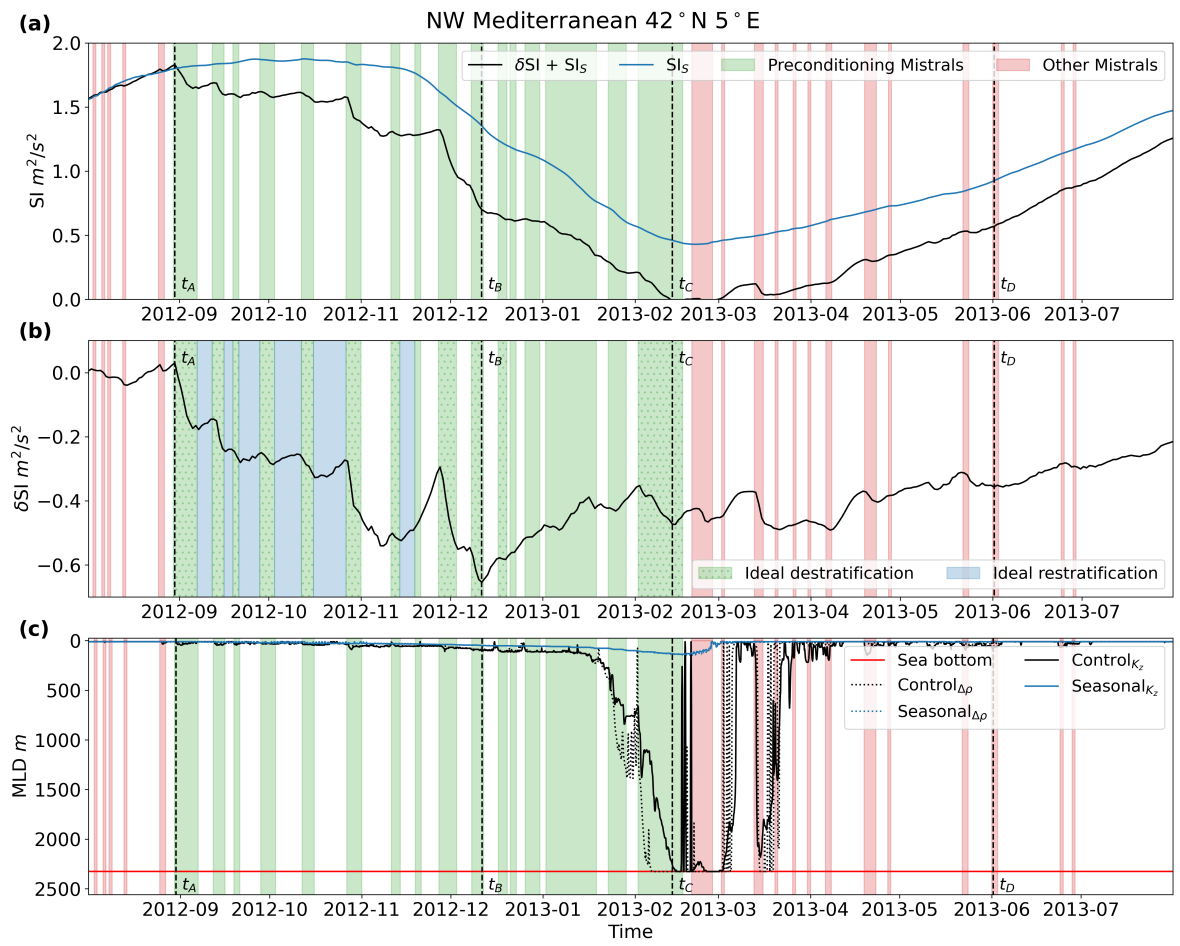

Figure 7. The Stratification Index of the nearest NEMO grid point to $42^{\circ} \mathrm{N} 5^{\circ} \mathrm{E}$ and MLD over the year of both simulations. Plot (a) shows the Stratification Index for the Control run, $S I_{S}+\delta S I$, and the Seasonal run, $S I_{S}$. Plot (b) shows the difference between the Control and Seasonal Stratification Index, $\delta S I$. Plot (c) shows the MLD for both simulations. Mistral events are shown in all three plots: colored green for events during the preconditioning and deep convection phase and red for events outside of the preconditioning phase. Mistral events with dotted hatching (the blue colored intervening time between events) are used as ideal destratification (restratification) events to compute the simple model restoration coefficients. The specific timestamps $t_{A}$ through $t_{D}$ correspond to the timestamps of the plots in Fig. 6: Aug. 30th, 2012, Dec. 11th 2012, Feb. 13th, 2013, June 1st, 2013, respectively. Two definitions of MLD are plotted in (c): one calculated by a vertical change in density less than $0.01 \mathrm{~kg} / \mathrm{m}^{3}$, denoted by $\Delta \rho$, and one calculated by a vertical diffusivity less than $5 \times 10^{-4} \mathrm{~m}^{2} / \mathrm{s}$, denoted by $K_{z}$. The MLD denoted by the vertical diffusivity criteria follows the turbocline depth and is taken to represent the mixed layer depth more accurately, as it matches the deep convection timing in the Stratification Index.

maximum destratification that the anomaly timescale provides is not enough to overcome the initial stratification. This means that both the intra-monthly and the inter-monthly variability of the buoyancy loss, reflected in $\delta S I+S I_{S}$, are required for deep convection to occur.

Another significant result is the timing of the deep convection. Deep convection initially occurs on Feb. 13th, 2013, which is before $S I_{S}$ reaches its minimum on Feb. 21th, 2013, but after $\delta S I$ reaches its minimum on Dec. 11th, 2012. After $\delta S I$ reaches its minimum, it stays around $-0.43 \mathrm{~m}^{2} / \mathrm{s}^{2}$ until May 2013, where it starts to increase. This means that while the induced destratification from the anomaly scale forcing would have been able to overcome $0.6 \mathrm{~m}^{2} / \mathrm{s}^{2}$ of stratification to form 
deep convection in Dec., the seasonal stratification was only low enough in Feb. for both $\delta S I$ and $S I_{S}$ to have a combined destratification strong enough for the water column to mix. In other words, the seasonal atmospheric forcing destratified the already preconditioned water column into deep convection. This means buoyancy loss due to the anomaly forcing is not what triggers deep convection, at least for this year, even though deep convection initially occurs near the end of a Mistral event.

\subsection{Simple model derivation}

To connect the Mistral to the ocean's response, we make the assumption that the response is a superposition of the seasonal response and the anomaly response. This means the effects of the Mistral can be categorized as anomalies affecting the short term time scale and studied separately from the seasonal response. In terms of the Brunt-Väisälä frequency, this linear combination is represented by $N^{2}=\delta N^{2}+N_{S}^{2}$, where $\delta$ denotes the anomaly terms and $S$ denotes the seasonal terms. To determine the Mistral's effect, we derive a simple model to describe the $S I$ of the water column in response to atmospheric forcing (note: the full derivation is found in App. A1). We start with the energy equation for incompressible fluids (White, 2011), then multiply the equation by $-g / T_{0}$ to express the energy equation in terms of buoyancy, assuming that the ocean's density varies negatively proportionally with temperature, $\rho=-\beta T$. We then perform partial differentiation with respect to $z$ to obtain an equation describing the Brunt-Väisälä frequency, $N^{2}$, in response to the atmospheric forcing, given by a forcing function, $F(t)$. Separating by timescale, we arrive at the following partial differential equations:

$$
\begin{aligned}
\frac{D \delta N^{2}}{D t} & =-\delta F(t) \\
\frac{D N_{S}^{2}}{D t} & =-F_{S}(t)
\end{aligned}
$$

$F(t)$ is preceded by a minus sign for ease in derivation, as positive quantities of $F(t)$ mean heat, hence buoyancy, is removed from the water column.

To simplify the seasonal time scale, we assume $N_{S}^{2}$ is only a function of time, $t$ :

$$
\frac{\mathrm{d} N_{S}^{2}}{\mathrm{~d} t}=-F_{S}(t)
$$

Assuming a homogeneous seasonal Brunt-Väisälä frequency over the depth of the water column gives us the relation for the seasonal Stratification Index, $S I_{S}$, and seasonal atmospheric forcing:

$\frac{\mathrm{d} S I_{S}}{\mathrm{~d} t}=-\frac{D^{2}}{2} F_{S}(t)$

To simplify the analytical solution for the anomaly timescale, we describe the advection term, $\boldsymbol{V} \cdot \nabla\left(\delta N^{2}\right)$, as a restoring term, $R=\alpha\left(\delta N^{2}\right)$, which relates the overall Brunt-Väisälä frequency to its seasonal component, $N_{S}^{2}$, using the linear assumption made before. This means the restoring coefficient, $\alpha$, represents the advective operation. This results in the following differential equation: 


$$
\frac{\partial \delta N^{2}}{\partial t}+\alpha\left(\delta N^{2}\right)=-\delta F(t)
$$

\subsection{Seasonal solution and forcing}

The solution for the seasonal timescale is relatively straight forward. As shown before, Eq. (9) relates the seasonal stratification, $S I_{S}$, to the seasonal atmospheric forcing, $F_{S}(t)$. We have the following definition of $F_{S}(t)$ from App. A1:

$F_{S}(t)=\frac{\partial}{\partial z}\left(\frac{\mathbf{q}_{\mathbf{a}, \mathbf{s}} g}{\rho c_{p} T_{0}}\right)=\frac{g}{\rho c_{p} T_{0}} \frac{\partial \mathbf{q}_{\mathbf{a}, \mathbf{s}}}{\partial z}$

where $c_{p}$ is the specific heat capacity of water, taken as $4184 \mathrm{Jkg}^{-1} \mathrm{~K}^{-1}, g$ is gravity, $\rho$ is the density of water, taken as 1000 $\mathrm{kgm}^{-3}$, and $T_{0}$ is the reference temperature, taken as the average seasonal sea surface temperature of $292.4 \mathrm{~K}$. This means $S I_{S}$ can be related to the seasonal volumetric atmospheric heat transfer, qa,s. Setting $\mathbf{q}_{\mathbf{a}, \mathbf{s}}=-Q_{n e t, S} / D$, where $Q_{n e t, S}$ is the seasonal net downward heat flux at the ocean surface from Eq. (2), we can calculate $\frac{\mathrm{d} S I_{S}}{\mathrm{~d} t}$ from $Q_{n e t, S}$. If we integrate both sides of Eq. (9) by $z$, after plugging in Eq. (11) and the relationship for $Q_{n e t, S}$, as $S I_{S}$ is constant with respect to (w.r.t.) $z$, Eq. (9) becomes:

$\frac{\partial S I_{S}}{\partial t}=\frac{g}{2 \rho c_{p} T_{0}} Q_{n e t, S}$

$\frac{g}{2 \rho c_{p} T_{0}} \approx 10^{-9}$, which means the derivative of $S I_{S}$ w.r.t. time, $t$, multiplied by $10^{9}$ is on the same order of magnitude as $Q_{n e t}$ (with the subscript $S$ now dropped for convenience, as the rest of the subsection discusses seasonal heat fluxes), which is what we see in Fig. 8 (a), with $\frac{\mathrm{d} S I_{S}}{\mathrm{~d} t} \times 10^{9}$ following the curve of $Q_{n e t}$. This relationship means when $Q_{n e t}$ crosses zero with a negative derivative, $S I_{S}$ experiences a maximum and vice versa for a minimum. Additionally, the longer $Q_{n e t}$ remains negative, the more seasonal destratification is incurred by the ocean. The seasonal variation of $Q_{\text {net }}$ is primarily driven by the solar radiation, $Q_{S W}$, which is evident in Fig. 8 (b). Consequently, the maximum and minimum values for $S I_{S}$ occur around Sept. 21st and March 21st, the fall and spring equinoxes. The asymmetry in $Q_{n e t}$ is mostly caused by the slightly seasonally varying latent heat flux, $Q_{E}$, followed by the sensible heat flux, $Q_{H}$, both of which also decrease the net heat flux by roughly $100 \mathrm{~W} / \mathrm{m}^{2}$ to $200 \mathrm{~W} / \mathrm{m}^{2}$, depending on the time of the year. $Q_{L W}$ remains roughly constant during the year, decreasing $Q_{n e t}$ by roughly $-100 \mathrm{~W} / \mathrm{m}^{2}$. These results are corroborated by the results of multiple model reanalysis for the region as well (Song and $\mathrm{Yu}, 2017)$.

Equation (12) and Fig. 8 convey that the seasonal stratification is primarily driven by shortwave downward radiation. The other terms, the longwave, latent heat, and sensible heat, shift the net heat flux negative enough for the ocean to have a destratification/restratification cycle. If the net heat flux was always positive, stratification would continue until the limit of the simple model applicability. This is an important finding, as, if future years feature less latent and sensible heat exchange due to warming or more humid winters, there will be less seasonal destratification, requiring more destratification from the anomaly 


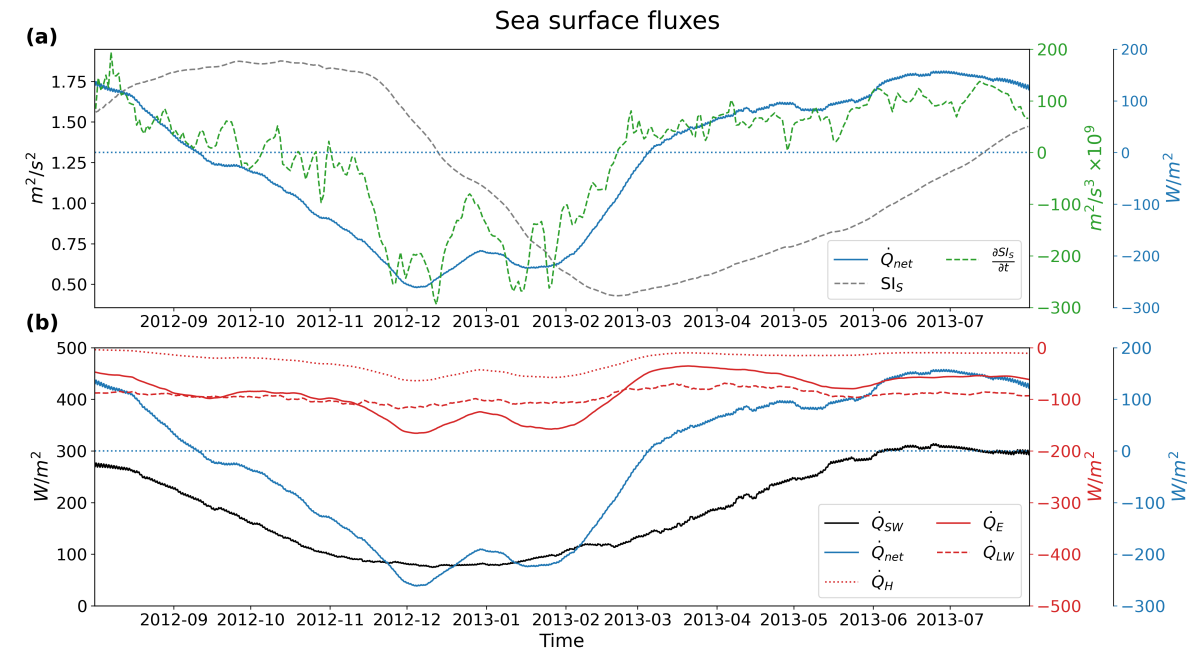

Figure 8. The smoothed (with Eq. (3)) seasonal surface heat fluxes over the point $42^{\circ} \mathrm{N} 5^{\circ} \mathrm{E}$ for the Seasonal simulation. (a) contains the seasonal stratification index, $S I_{S}$, and its derivative, $\frac{\partial S I_{S}}{\partial t}$, comparing it to the seasonal net heat flux, $Q_{\text {net }}$ (the subscript $S$ is dropped for convenience). (b) shows the net heat flux separated into its components: $Q_{E}, Q_{H}, Q_{S W}$, and $Q_{L W}$ for latent heat, sensible heat, shortwave downward, and longwave downward fluxes, respectively. The different line colors correspond to the similarly colored axes.

timescale to cause deep convection. Consecutive years of decreasing latent and sensible heat fluxes could form a water column that is too stratified to allow deep convection to occur.

\subsection{Anomaly solution and forcing}

To solve for the anomaly timescale, described by Eq. (10), we assume $\delta F(t)$ can be represented by a pulse function shown in Fig. 9. This pulse function assumes the primary forcing at the anomaly timescale is represented by Mistral events. Each Mistral event, $k$, has a duration, $\Delta t_{k}$, and a period between the start of the current and following event, $\Delta \tau_{k} . \delta F_{k}$ is the strength of the forcing for each event. Inserting this into Eq. (10) allows us to solve it in a piecewise manner. Like we did for the seasonal time scale, we assume the water column has a homogeneous Brunt-Väisälä frequency, allowing us to make use of Eq. (6). The restoring coefficient then only represents the horizontal advection, as the vertical component becomes zero with our assumption of a homogeneous $N^{2}$. The last assumption is the restoring coefficient remains constant for each section of the forcing function:

$\delta S I_{k}(t)= \begin{cases}{\left[\delta S I_{k-1}\left(t_{k}\right)+\frac{\delta F_{k}}{\alpha_{d}}\left(1-e^{\alpha_{d}\left(t-t_{k}\right)}\right)\right] e^{-\alpha_{d}\left(t-t_{k}\right)}} & {\left[t_{k}, t_{k}+\Delta t_{k}\right)} \\ {\left[\delta S I_{k-1}\left(t_{k}\right)+\frac{\delta F_{k}}{\alpha_{d}}\left(1-e^{\alpha_{d} \Delta t_{k}}\right)\right] e^{\left(\alpha_{a}-\alpha_{d}\right) \Delta t_{k}-\alpha_{a}\left(t-t_{k}\right)}} & {\left[t_{k}+\Delta t_{k}, t_{k}+\Delta \tau_{k}\right)}\end{cases}$

where $\alpha_{d}$ and $\alpha_{a}$ are the restoring coefficients during $\left(\left[t_{k}, t_{k}+\Delta t_{k}\right)\right)$ and after $\left(\left[t_{k}+\Delta t_{k}, t_{k}+\Delta \tau_{k}\right)\right)$ a Mistral event, respectively. 


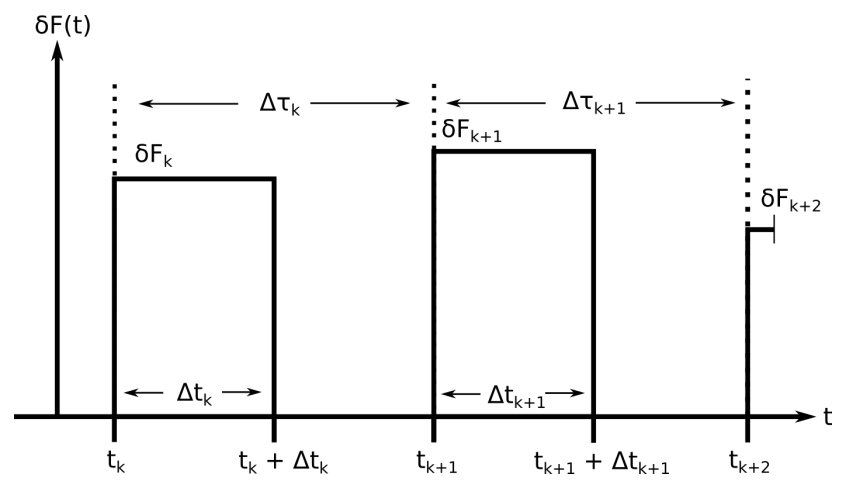

Figure 9. The Mistral forcing as a pulse function used to solve Eq. (10). $k$ corresponds to the event and $\delta F_{k}$ corresponds to the forcing strength of the Mistral event. $\Delta t_{k}$ corresponds to the duration of the of the Mistral event, and $\Delta \tau_{k}$ to the period between events, with $t_{k}$ denoting the start of event $k$.

Further assuming $\delta F_{k}=\delta F, \Delta t_{k}=\Delta t$, and $\Delta \tau_{k}=\Delta \tau$ for all $k$, which results in a periodic pulse function with constant amplitude and period, we can simplify Eq. (13) using the sum of a finite geometric series. At the beginning of the preconditioning period, destratification hasn't yet begun, therefore the initial $\delta S I$ is zero, resulting in the following equation set:

$\delta S I_{k}(t)= \begin{cases}\frac{D^{2}}{2} \frac{\delta F}{\alpha_{d}}\left[\left(1-e^{\alpha_{d} \Delta t}\right)\left(\frac{1-e^{\left[\left(\alpha_{a}-\alpha_{d}\right) \Delta t-\alpha_{a} \Delta \tau\right] k}}{1-e^{\left[\left(\alpha_{a}-\alpha_{d}\right) \Delta t-\alpha_{a} \Delta \tau\right]}}-1\right)+\left(1-e^{\alpha_{d}\left(t-t_{k}\right)}\right)\right] e^{-\alpha_{d}\left(t-t_{k}\right)} & {\left[t_{k}, t_{k}+\Delta t_{k}\right)} \\ \frac{D^{2}}{2} \frac{\delta F}{\alpha_{d}}\left[\left(1-e^{\alpha_{d} \Delta t}\right)\left(\frac{1-e^{\left[\left(\alpha_{a}-\alpha_{d}\right) \Delta t-\alpha_{a} \Delta \tau\right] k}}{1-e^{\left[\left(\alpha_{a}-\alpha_{d}\right) \Delta t-\alpha_{a} \Delta \tau\right]}}-1\right)+\left(1-e^{\alpha_{d} \Delta t_{k}}\right)\right] e^{\left(\alpha_{a}-\alpha_{d}\right) \Delta t_{k}-\alpha_{a}\left(t-t_{k}\right)} & {\left[t_{k}+\Delta t_{k}, t_{k}+\Delta \tau_{k}\right)}\end{cases}$

This final equation set allows us to describe the integrated effect of consecutive Mistrals and to easily pick apart the effects of the Mistral's different attributes, including the frequency of events.

To determine the value of the restoring coefficients, a normalized function was derived for each section of a Mistral event (derivation shown in App. A2.1 for during an event and App. A2.2 for after an event). The resulting normalized functions were fitted against the NEMO $\delta S I$ results in Fig. 7 for the denoted ideal events in Table 1 (denoted d for the dates with ideal destratification taking place during the event and a for the dates with ideal restratification taking place after the event) and given the average event values of $\overline{\Delta t}=5.69$ days and $\overline{\Delta \tau}=10.88$ days. The result of the fitting is shown in Fig. 10, with $\alpha_{d}$ having a fitted valued of $0.235 \mathrm{day}^{-1}$ and $\alpha_{a}$ having a fitted value of $0.021 \mathrm{day}^{-1}$. If we recall the meaning of $\alpha_{d}$ and $\alpha_{a}$ from the derivation of the simple model in Sec. 3.3, this means the advective term in Eq. (10) has a larger role in the destratification phase of the Mistral event than in the restratification phase, as it is an order of magnitude larger. This result suggests horizontal mixing occurs between events, as a smaller value for the restoration coefficient during the restratification phase means the existence of weaker horizontal gradients than during the preceding destratification phase. 

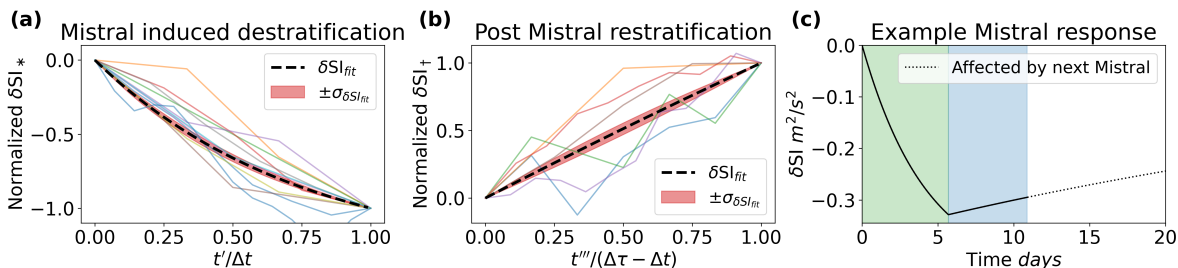

Figure 10. The normalized theoretical solutions (Eq. (A42) and (A48)) for during, (a), and after, (b), a destratification event fitted to the ideal Mistral events from Table 1 and $\delta S I$ values from the NEMO results in Fig. 7. A value of $0.235 d a y^{-1}$ for $\alpha_{d}$ and a value of $0.021 d a y^{-1}$ for $\alpha_{a}$ was found. Plot (c) shows the $\delta S I$ response using the determined restoration coefficients, given an ideal Mistral event with the average values of 5.69 days for the duration and 10.88 days for the period. The average strength of a Mistral, $\delta F=4.01 \times 10^{-8} s^{-2} d a y s^{-1}$, was taken from values found in Table A1 from the Appendix.

The strength of each Mistral event, $\delta F_{k}$, was found in similar way by solving for $\delta F_{k}$ after noting the initial value of $\delta S I_{k}\left(t_{k}\right)$ is equal to $\delta S I_{k-1}\left(t_{k}\right)$ (derivation found in App. A3). Then the values of $\delta S I$ from the NEMO results in Fig. 7 were plugged in to determine the values of $\delta F_{k}$ (see Table $\mathrm{A} 1$ in the appendix for the resulting values).

\subsubsection{Mistral strength and destratification}

Mistral events do not always lead to destratification. Some events in Fig. 7 fail to create further destratification and actually continue to restratify the water column. The simple model can describe this phenomena. To determine which events lead to destratification versus not, we take the derivative with respect to time of Eq. (13) for during an event. This results in the following equation:

$\frac{\partial \delta S I_{k}(t)}{\partial t}=-\alpha_{d}\left[\delta S I_{k-1}\left(t_{k}\right)+\frac{D^{2}}{2} \frac{\delta F_{k}}{\alpha_{d}}\right] e^{-\alpha_{d}\left(t-t_{k}\right)}$

The quantity $\frac{\partial \delta S I_{k}(t)}{\partial t}$ must be less than zero for destratification to occur, which means if $\alpha_{d}$ is a positive quantity (refer to App. A2 or Fig. 10), $\delta S I_{k-1}\left(t_{k}\right)+\frac{D^{2}}{2} \frac{\delta F_{k}}{\alpha_{d}}$ must be a positive quantity. If some destratification has already occurred relative

310 to the seasonal stratification, such that $\delta S I_{k-1}\left(t_{k}\right)<0$, then $\frac{D^{2}}{2} \frac{\delta F_{k}}{\alpha_{d}}$ must be larger than $-\delta S I_{k-1}\left(t_{k}\right)$ for destratification to occur. Recalling that $\delta F_{k}$ is positive when heat is removed from the water column, this means that additional Mistral events must overcome the current amount of destratification to further destratify the water column. Otherwise, no destratification occurs or even restratification occurs. An example of this can be seen with the Mistral event starting on Jan. 2nd, 2013, that lasts for 17 days in Fig. 7 (b). The event starts off with an initial destratification of $-0.48 \mathrm{~m}^{2} / \mathrm{s}^{2}$ and ends at $-0.41 \mathrm{~m}^{2} / \mathrm{s}^{2}$, a net restratification of $0.07 \mathrm{~m}^{2} / \mathrm{s}^{2}$. This is despite the fact this event has a positive $\delta F_{k}$ value of $3.80 \times 10^{-8} \mathrm{~s}^{-2} d a y^{-1}$ (from Table A1).

The combined overall effect of this result can be seen in Fig. 7 (b), as the consecutive Mistral events during the preconditioning phase cause destratification to a minimum of $-0.6 \mathrm{~m}^{2} / \mathrm{s}^{2}$ for $\delta S I$ on Dec. 11th, 2012. Proceeding events after this minimum fail to continue to destratify the water column and, instead, restratification occurs on the anomaly time scale, even 
before deep convection occurs. The seasonal stratification, $S I_{S}$, and not the anomaly destratification, $\delta S I$, brings the total $S I$ to zero on Feb. 13, 2013, resulting in deep convection.

\subsubsection{Dominating Mistral attribute}

A pertinent question to ask is which attribute of the Mistral, the frequency, strength, or duration, is the most important when it drives destratification. Figure 12 and 11 show the results of varying $\delta F, \Delta t$, and $\Delta \tau$ individually (in subplots (a), (b), and (c)), respectively) in Eq. (14). The other variables are kept at the mean value when not varied. The dashed lines in both figures show the limit of potential destratification per case. What we can see is stronger Mistral events, with an increased value for $\delta F$, result in more destratification, with the reverse happening with decreased values. Decreasing the event duration, $\Delta t$, results in less destratification, however, increasing event duration causes more destratification up to the limit where the individual events converge into one single long event and the destratification converges to the dashed line limit. After this, there is no additional destratification. Increasing or decreasing the frequency of events (decreasing or increasing the period, $\Delta \tau$ ), only minimally changes the accrued destratification, due to the fact that the magnitude of $\frac{\partial \delta S I}{\partial t}$ is dependent on the strength of the current Mistral event and the already achieved destratification. Decreasing the frequency (increasing the period), allows for more restratification to occur after an event, but the proceeding event has a larger difference between current destratification and the event strength, leading to destratification that almost reaches the same level as the case with more frequent events. Increasing the frequency has a similar effect to increasing the duration; when the period is zero, the forcing becomes one large event, converging the resulting destratification to the dashed line.

To more accurately quantify the effect of each attribute, we separate $\delta S I$ into its total derivative in terms of the Mistral attributes:

$\mathrm{d} \delta S I=\underbrace{\frac{\partial \delta S I}{\partial \delta F} \mathrm{~d} \delta F}_{\text {Strength }}+\underbrace{\frac{\partial \delta S I}{\partial \Delta t} \mathrm{~d} \Delta t}_{\text {Duration }}+\underbrace{\frac{\partial \delta S I}{\partial \Delta \tau} \mathrm{d} \Delta \tau}_{\text {Period }}$

Due to the lack of available total derivatives for $\delta F, \Delta t$, and $\Delta \tau$, we approximate them with their respective standard deviation: $\sigma_{x} \approx \mathrm{d} x$. Before we determine the partial derivatives for each attribute, note that in Fig. 11 and 12 subplot $f$ that changing the number events, $k$, does not change the potential destratification limit (the dashed line). This means the potential destratification does not change with the number of events. Another notation to make is the character of the potential destratification limit: it approaches some asymptotic value as $k$ approaches infinity. We can take advantage of this by differentiating the destratification phase of Eq. set (14) with respect to $k$, taking $t=\Delta \tau$, at the end of the phase, where the destratification equals the potential destratification:

$\frac{\partial \delta S I_{k}\left(t=t_{k}+\Delta t\right)}{\partial k}=\frac{D^{2}}{2} \frac{\delta F}{\alpha_{d}} \frac{\left(e^{-\alpha_{d} \Delta t}-1\right)}{\left(1-e^{\left(\alpha_{a}-\alpha_{d}\right) \Delta t-\alpha_{a} \Delta \tau}\right)}\left(-e^{\left[\left(\alpha_{a}-\alpha_{d}\right) \Delta t-\alpha_{a} \Delta \tau\right] k}\right)\left(\left(\alpha_{a}-\alpha_{d}\right) \Delta t-\alpha_{a} \Delta \tau\right)$ 
https://doi.org/10.5194/os-2021-72

Preprint. Discussion started: 9 August 2021
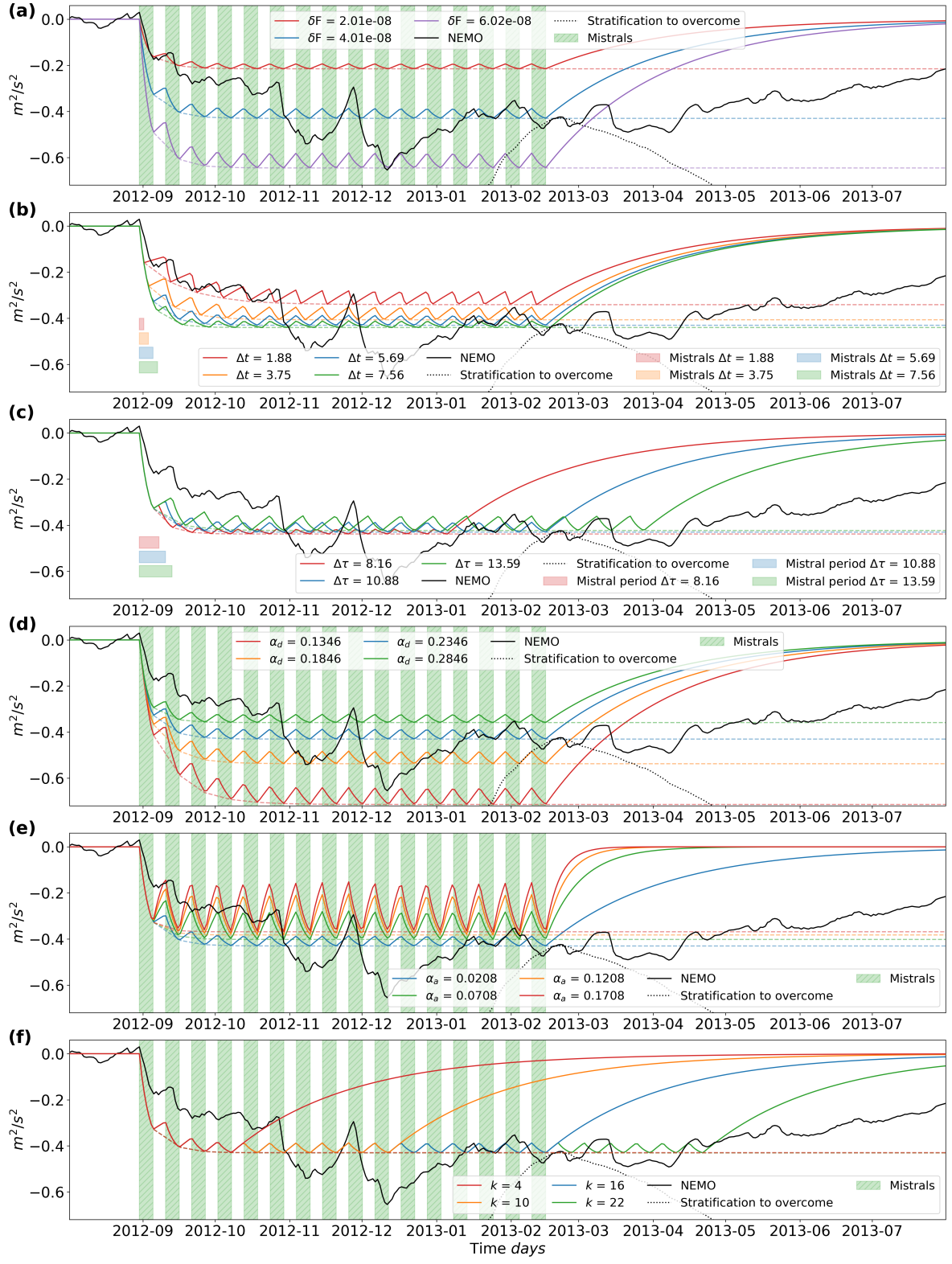

Figure 11. Equation (14) plotted with one variable varying in each plot with the other variables held constant at the mean value. (a) varies the strength of the Mistral, $\delta F$, (b) varies the duration, $\Delta t$, and (c) varies the period between events, $\Delta \tau$. (d) varies the restoration coefficient during the destratification phase, $\alpha_{d}$ and (e) varies the restoration coefficient for the restratification phase. (f) varies the number of events.

Plugging in the mean values of $\Delta t, \Delta \tau$, and $\Delta F$, and taking $k=16$, for the 16 events that occurred during the preconditioning phase, the above derivative equates a very small value of $-5.93 \times 10^{-11} \mathrm{~m}^{2} / \mathrm{s}^{2}$ per event. This confirms the small change in the potential destratification with increasing events. Taking $k$ to infinity and noting that $\alpha_{d}>\alpha_{a}$ : 

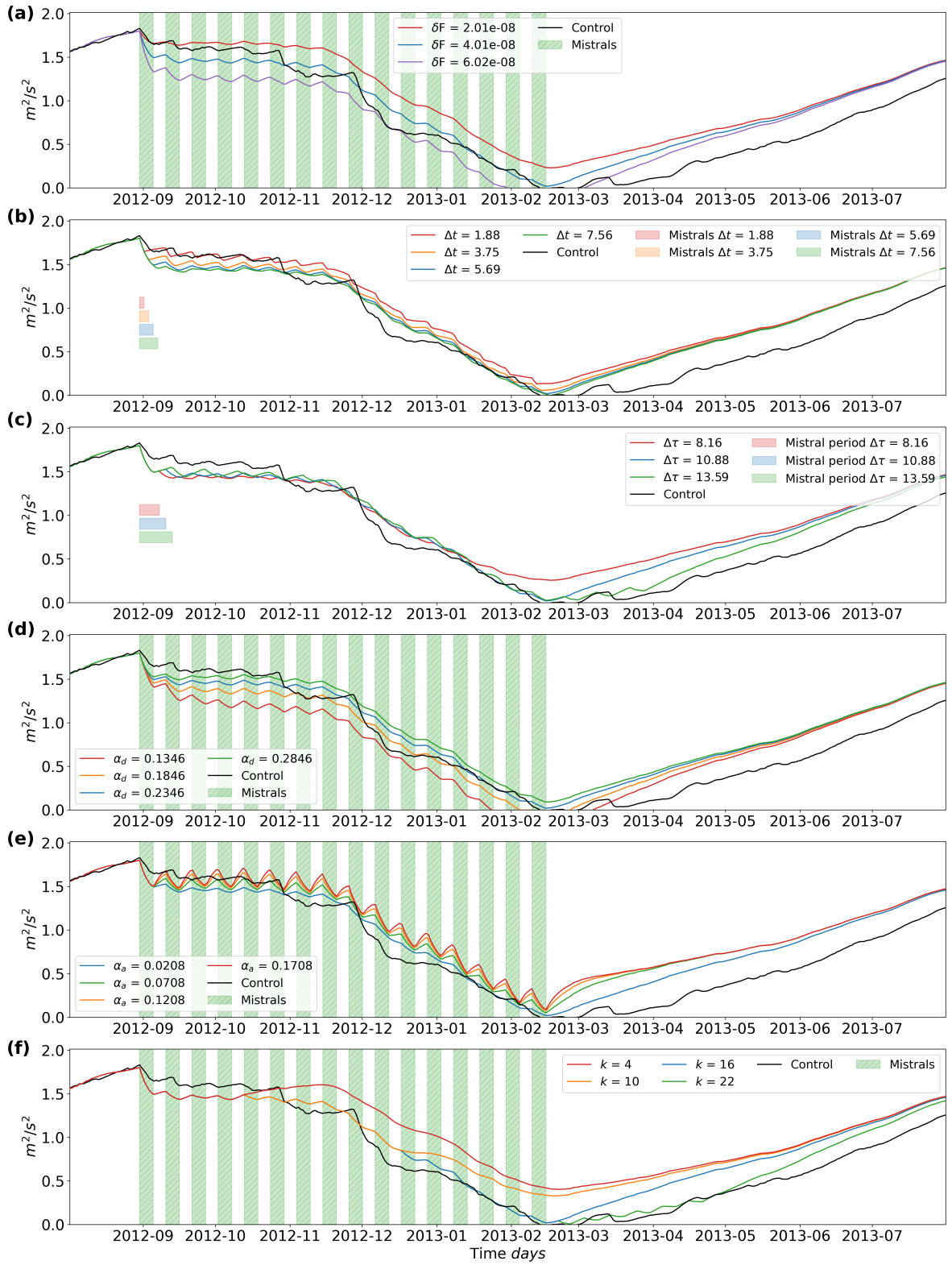

Figure 12. Same as Fig. 11, however, $S I_{S}$ is added to the results from Eq. (14).

$\delta S I_{\infty}=\delta S I_{\infty}\left(t=t_{k}+\Delta t\right)=\frac{D^{2}}{2} \frac{\delta F}{\alpha_{d}}\left(e^{-\alpha_{d} \Delta t}-1\right)\left(\frac{1}{1-e^{\left(\alpha_{a}-\alpha_{d}\right) \Delta t-\alpha_{a} \Delta \tau}}\right)$

We have an equation that describes the potential destratification, $\delta S I_{\infty}$, in terms of the Mistral attributes, independent of the number of events. Differentiating by the different attributes (see App. A5 for the resulting analytical derivations) and 
plugging in the mean values where appropriate, we arrive at the resulting values: The derivative w.r.t. the strength of the

Mistrals, $\partial \delta S I_{\infty} / \partial \Delta F$, equals a value of $-1.07 \times 10^{7} \mathrm{~m}^{2} d a y$, the derivative w.r.t. duration, $\partial \delta S I_{\infty} / \partial \Delta t$, equals $-7.60 \times 10^{-3}$ $\mathrm{m}^{2} / \mathrm{s}^{2} d a y$, and the derivative w.r.t. the period, $\partial \delta S I_{\infty} / \partial \Delta \tau$, equals $2.77 \times 10^{-3} \mathrm{~m}^{2} / \mathrm{s}^{2}$ day (larger periods mean less frequent Mistral events, hence less destratification), respectively. Replacing $\delta S I$ with $\delta S I_{\infty}$ in Eq. (16), we can now multiply the partial derivatives with the standard deviations to determine which attribute leads to the most potential destratification. The strength term is equal to $-1.28 \times 10^{-1} \mathrm{~m}^{2} / \mathrm{s}^{2}$, the duration term has a value of $-3.21 \times 10^{-2} \mathrm{~m}^{2} / \mathrm{s}^{2}$, and the period term has a value of $1.27 \times 10^{-2} \mathrm{~m}^{2} / \mathrm{s}^{2}$. With the strength term an order of magnitude larger than the other two terms, according to this simple model, the strength of the Mistral event is the most sensitive attribute when it comes to the effect of the Mistral on destratification, followed by its duration.

\subsection{Simple model results}

A complete and average Mistral destratification and restratification event according to Eq. (14) is given in Fig. $10 c$, which took the average Mistral values from Table 1 and A1, and the restoring coefficients from App. A2. During the event, marked in green, the Mistral causes destratification. After the event, marked in blue, the ocean column restratifies until another event occurs (denoted by the dashed line). This is the same behavior we see in Fig. 7.

If we put together Eq. (13) with the duration and period information from Table 1, and Mistral strength information from Table A1, we can create a time series of $\delta S I$ to compare the integrated response of the simple model to the NEMO model results. This comparison is presented in Fig. 13. The simple model results resemble the NEMO simulation results quite well, which is expected as the fitted values for the restoring coefficients and the values for the Mistral event strengths are extracted from the NEMO model results. However, this means that a series of variable pulse like Mistral events can recreate with decent accuracy the patterns that we see in the NEMO results for $\delta S I$. This essentially confirms that the Mistral events are the primary driving component of heat loss at the anomaly time scale leading to destratification.

\section{Conclusions}

The 2012-2013 deep convection year in the Gulf of Lion was investigated to determine the effect the Mistral winds have on deep convection. Two NEMO ocean simulations were run, one forced with unmodified WRF/ORCHIDEE atmospheric forcing (Control) and one forced with atmospheric fields filtered to remove the Mistral signature (Seasonal). Separating the atmospheric forcing into the long-term and anomaly timescales revealed that the Mistral winds do not act alone to destabilize the northwestern Mediterranean Sea. Both the seasonal atmospheric change, reflected in the long-term timescales, and the Mistral winds, reflected in the anomaly timescales, combine to destabilize and destratify the water columns in the Gulf of Lion in roughly equal amounts (favoring the seasonal change).

When the NEMO simulation results were probed further by developing a simple model, the simple model results confirmed the hypothesis that Mistrals act on the anomaly timescale to destratify the water column. These results further conveyed that additional Mistrals need to be stronger in terms of heat transfer than previous events to create further destratification. Otherwise, 


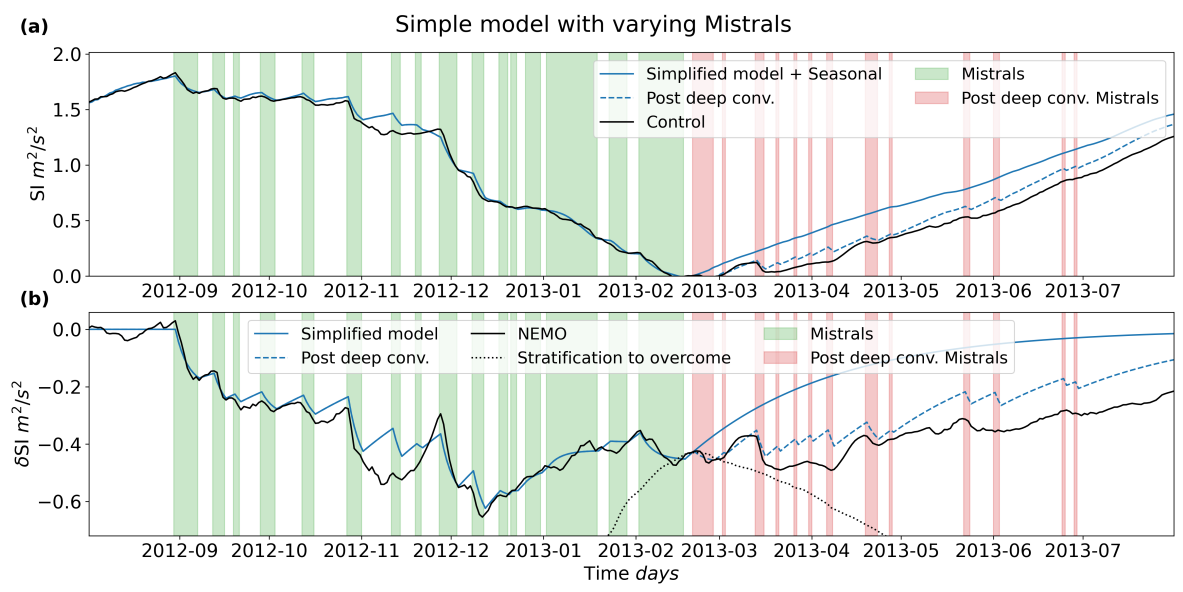

Figure 13. The combined effect of Eq. (13) for multiple Mistrals with the Mistral data from Table 1 and A1. (a) shows the calculated $\delta S I+S I_{S}$ response, while (b) is the calculated simple model $\delta S I$ versus the NEMO $\delta S I$ simulation results. Effects from Mistrals after deep convection are included with the dashed blue line and show that Mistrals after deep convection can retard the proceeding restratification during the restratification phase.

no destratification, or even restratification, occurs. The simple model then goes on to reveal, after some additional derivation, that the most important part of a Mistral event is its strength, in regards to potential destratification. Changing the duration or frequency has an effect, but this effect is on a order of magnitude smaller than changing the Mistral strength.

The simple model also conveyed the underlying drivers of the long-term, or seasonal timescale. The evolution of the seasonal Stratification Index is equal to the next heat flux leaving the ocean. As the net heat flux follows the shape of the incoming solar radiation, the maximum and minimum values for the seasonal Stratification Index occur around Sept. 21st and March 21st, respectively, or the fall and spring equinoxes. Shifted negative by the latent, sensible, and longwave radiation heat fluxes, the net heat flux allows for a seasonal cycle of destratification during the winter and restratification during the summer. If any of the three negative shifting components are unable to cool the ocean surface enough, deep convection may fail to appear, unless the contribution of the Mistral winds is able to compensate.

However, some of the NEMO simulation results bring further questions. Sec. 3 noted that the seasonal change in stratification brought the preconditioned water columns in the Gulf of Lion to the point of deep convection, for the winter of 2012-2013, as the Mistral-induced preconditioning had already passed its minimum destratification beforehand. This brings up the question of whether or not this occurs for all deep convection events, or if it is possible for Mistral events to destratify the water columns to the point of overturning after the seasonal minimum, essentially meaning the Mistral-induced destratification "catches up" to the seasonal destratification. Another question brought around by the simulation results is the effect of initial stratification at the beginning of the preconditioning phase on the Gulf of Lion's ability to form deep convection for a given year. This question has been investigated and partially answered in Somot et al. (2016), however we believe the method of separating the 
https://doi.org/10.5194/os-2021-72

Preprint. Discussion started: 9 August 2021

(c) Author(s) 2021. CC BY 4.0 License.

atmospheric forcing into the seasonal and anomaly components will reveal more answers to this question. These questions will

be investigated further in different studies.

\section{Appendix A: Equations}

\section{A1 Simple Stratification Index model}

The purpose of this simple model is to separate the seasonal scale atmospheric forcing from the anomaly scale forcing. We start the derivation with the energy equation for incompressible flow (White, 2011):

$410 \rho c_{p} \frac{D T}{D t}=\frac{D \mathbf{q}}{D t}$

where $\rho$ is density, $c_{p}$ is the specific heat of the fluid with constant pressure, $T$ is temperature, $t$ is time, and $\mathbf{q}$ is energy per volume from heat. $\frac{D}{D t}$ is the material derivative.

In this model we're assuming the heat transfer term is equal to the heat removed by the atmosphere:

$$
\frac{D \mathbf{q}}{D t}=-\mathbf{q}_{\mathbf{a}}
$$

415 where $\mathbf{q}_{\mathbf{a}}$ is the volumetric heat forcing from the atmosphere. This leaves us with the following equation:

$$
\frac{D T}{D t}=-\frac{\mathbf{q}_{\mathbf{a}}}{\rho c_{p}}
$$

The Brunt-Väisälä frequency is defined as:

$$
N^{2}=\frac{\partial b}{\partial z}=-\frac{g}{\rho_{0}} \frac{\partial \rho}{\partial z}
$$

Assuming a fluid whose density varies negatively proportionally to the temperature, $\rho=-\beta T$, which is an acceptable approximation as the density only varies only a few tenths of a $\mathrm{kg} / \mathrm{m}^{3}$ and temperature only varies about 10 degrees Celsius, we can describe $N^{2}$ in terms of temperature:

$N^{2}=\frac{\partial b}{\partial z}=-\frac{g}{T_{0}} \frac{\partial T}{\partial z}$

Introducing buoyancy as $b=-\frac{g}{T_{0}} T$, we can rearrange the energy equation into terms of buoyancy:

$$
\frac{g}{T_{0}}\left[\frac{D T}{D t}=-\frac{\mathbf{q}_{\mathbf{a}}}{\rho c_{p}}\right] \Rightarrow \frac{D b}{D t}=-\frac{\mathbf{q}_{\mathbf{a}} g}{\rho c_{p} T_{0}}
$$


https://doi.org/10.5194/os-2021-72

Preprint. Discussion started: 9 August 2021

(c) Author(s) 2021. CC BY 4.0 License.

425 If we then differentiate by $\frac{\partial}{\partial z}$, we can reorganize the equation in terms of the Brunt-Väisälä frequency, $N^{2}$ :

$\frac{\partial}{\partial z}\left(\frac{D b}{D t}=-\frac{\mathbf{q}_{\mathbf{a}} g}{\rho c_{p} T_{0}}\right) \Rightarrow \frac{D N^{2}}{D t}=-\frac{\partial}{\partial z}\left(\frac{\mathbf{q}_{\mathbf{a}} g}{\rho c_{p} T_{0}}\right)$

By renaming the atmospheric forcing term on the right hand side of Eq. (A7) to $F(t)$, we can make this equation easier to follow:

$F(t)=\frac{\partial}{\partial z}\left(\frac{\mathbf{q}_{\mathbf{a}} g}{\rho c_{p} T_{0}}\right)$

This brings us to:

$\frac{D N^{2}}{D t}=-F(t)$

The main assumption we make is that the ocean column is a linear system and responds to the large and short/anomaly time scale atmospheric forcing independently:

$$
\begin{aligned}
N^{2} & =N_{S}^{2}+\delta N^{2} \\
F(t) & =\delta F(t)+F_{S}(t)
\end{aligned}
$$

which describes the response of $N^{2}$ on the anomaly timescale, $\delta N^{2}$ :

$\frac{D \delta N^{2}}{D t}=-\delta F(t)$

and the response of $N^{2}$ on the seasonal timescale, $N_{S}^{2}$ :

$\frac{D N_{S}^{2}}{D t}=-F_{S}(t)$

For the seasonal response, we further make the assumption that $N_{S}^{2}$ negligibly depends on the $x, y$, and $z$ coordinate direc440 tions:

$\frac{\mathrm{d} N_{S}^{2}}{\mathrm{~d} t}=-F_{S}(t)$

If we want to connect the overall Brunt-Väisälä frequency, $N^{2}$, to the seasonal one, $N_{S}^{2}$, we can formulate a restoring term, $R$, in terms of $T$, or in terms of $N^{2}$ following the steps mentioned above: 
https://doi.org/10.5194/os-2021-72

Preprint. Discussion started: 9 August 2021

(c) Author(s) 2021. CC BY 4.0 License.

$R=\frac{\partial}{\partial z}\left(\frac{g}{T_{0}} \alpha \rho c_{p}\left(T-T_{S}\right)\right) \Rightarrow \alpha\left(N^{2}-N_{S}^{2}\right)$

Or, with $\delta N^{2}=N^{2}-N_{S}^{2}$ :

$R=\alpha \delta N^{2}$

Where $\alpha$ is the restoring term coefficient. Separating the material derivative into its time and advective components for Eq. (A11):

$\frac{\partial \delta N^{2}}{\partial t}+\boldsymbol{V} \cdot \nabla\left(\delta N^{2}\right)=-\delta F(t)$

we will replace the advective component, $\boldsymbol{V} \cdot \nabla\left(\delta N^{2}\right)$, with $R$, which essentially swallows the advective operation into the restoring coefficient, $\alpha$. This results in the partial differential equation that we will study further:

$\frac{\partial \delta N^{2}}{\partial t}+\alpha \delta N^{2}=-\delta F(t)$

\section{A1.1 Solution for seasonal $S I$}

To solve the response of $N^{2}$ for the seasonal timescale, given by Eq. (A13), we will assume $N_{S}^{2}$ is vertically homogeneous, giving us the stratification index response, or Eq. (9), through the use of Eq. (6). We can then separate back out $F_{S}(t)$ into its components:

$F_{S}(t)=\frac{g}{\rho c_{p} T_{0}} \frac{\partial \mathbf{q}_{\mathbf{a}, \mathbf{S}}}{\partial z}$

Dividing $\mathbf{q}_{\mathbf{a}, \mathbf{S}}$ by $D$ gives us the atmospheric cooling in terms of a surface flux, $-Q_{n e t, S}$. If we plug this relationship back into Eq. (9), we get:

$460 \frac{\mathrm{d} S I_{S}}{\mathrm{~d} t}=\frac{D}{2} \frac{g}{\rho c_{p} T_{0}} \frac{\partial Q_{n e t, S}}{\partial z}$

Integrating this equation by $z$ gives us:

$$
\begin{aligned}
\int_{0}^{D} \frac{\mathrm{d} S I_{S}}{\mathrm{~d} t} \partial z & =\frac{D}{2} \frac{g}{\rho c_{p} T_{0}} \int_{0}^{D} \frac{\partial Q_{n e t, S}}{\partial z} \partial z \\
\frac{\mathrm{d} S I_{S}}{\mathrm{~d} t} D & =\frac{D}{2} \frac{g}{\rho c_{p} T_{0}} Q_{n e t, S} \\
\frac{\mathrm{d} S I_{S}}{\mathrm{~d} t} & =\frac{g}{2 \rho c_{p} T_{0}} Q_{n e t, S}
\end{aligned}
$$


https://doi.org/10.5194/os-2021-72

Preprint. Discussion started: 9 August 2021

(c) Author(s) 2021. CC BY 4.0 License.

And, therefore, we have $S I_{S}$ expressed in terms of $Q_{n e t, S}$.

\section{A1.2 Solution with Mistral forcing function}

Focusing on just the anomaly time scale, we will assume the Mistral is the primary source of forcing. To model the atmospheric cooling of the Mistral, we will model the forcing function, $\delta F(t)$, as a series of $k$ pulse functions, of magnitude $\delta F_{k}$, over a duration of $\Delta t_{k}$, and with a period of $\Delta \tau_{k}$, visualized in Fig. 9 .

To solve the Brunt-Väisälä frequency response with the Mistral pulse forcing function, we solve Eq. (A17) in a piecewise manner, with a solution for each section of the pulse function. We will also make the assumption that for each portion of the Mistral event, during and after, the advective components, hence $\alpha$, remain constant with respect to time. This leads to $\alpha_{d}$ and $\alpha_{a}$ representing the advective components during and after an event, respectively. During a Mistral event, $\left[t_{k}, t_{k}+\Delta t_{k}\right)$, we get:

$$
\begin{aligned}
\frac{\partial \delta N^{2}}{\partial t} & +\alpha_{d}\left(\delta N^{2}\right)=-\delta F(t) \\
\delta N_{k}^{2}(t) & =-\frac{\delta F_{k}}{\alpha_{d}}+c_{0} e^{-\alpha_{d} t} \\
\delta N_{k}^{2}\left(t_{k}\right) & =-\frac{\delta F_{k}}{\alpha_{d}}+c_{0} e^{-\alpha_{d} t_{k}}=\delta N_{k-1}^{2}\left(t_{k}\right) \\
c_{0} & =\left[\delta N_{k-1}^{2}\left(t_{k}\right)+\frac{\delta F_{k}}{\alpha_{d}}\right] e^{\alpha_{d} t_{k}}
\end{aligned}
$$

With the result:

$\delta N_{k}^{2}(t)=\left[\delta N_{k-1}^{2}\left(t_{k}\right)+\frac{\delta F_{k}}{\alpha_{d}}\left(1-e^{\alpha_{d}\left(t-t_{k}\right)}\right)\right] e^{-\alpha_{d}\left(t-t_{k}\right)}$

After the event, $\left[t_{k}+\Delta t_{k}, t_{k+1}\right)$ :

$$
\begin{aligned}
\frac{\partial \delta N^{2}}{\partial t} & +\alpha_{a}\left(\delta N^{2}\right)=0 \\
\delta N_{k}^{2}(t) & =c_{1} e^{-\alpha_{a} t} \\
\delta N_{k}^{2}\left(t_{k}+\Delta t_{k}\right) & =c_{1} e^{-\alpha_{a}\left(t_{k}+\Delta t_{k}\right)} \\
& =\left[\delta N_{k-1}^{2}\left(t_{k}\right)+\frac{\delta F_{k}}{\alpha_{d}}\left(1-e^{\alpha_{d} \Delta t_{k}}\right)\right] e^{-\alpha_{d} \Delta t_{k}} \\
c_{1} & =\left[\delta N_{k-1}^{2}\left(t_{k}\right)+\frac{\delta F_{k}}{\alpha_{d}}\left(1-e^{\alpha_{d} \Delta t_{k}}\right)\right] e^{\left(\alpha_{a}-\alpha_{d}\right) \Delta t_{k}-\alpha_{a} t_{k}}
\end{aligned}
$$

With the result:

$\delta N_{k}^{2}(t)=\left[\delta N_{k-1}^{2}\left(t_{k}\right)+\frac{\delta F_{k}}{\alpha_{d}}\left(1-e^{\alpha_{d} \Delta t_{k}}\right)\right] e^{\left(\alpha_{a}-\alpha_{d}\right) \Delta t_{k}-\alpha_{a}\left(t-t_{k}\right)}$ 
https://doi.org/10.5194/os-2021-72

Preprint. Discussion started: 9 August 2021

(c) Author(s) 2021. CC BY 4.0 License.

Or, to have the results more succinctly put:

$\delta N_{k}^{2}(t)= \begin{cases}{\left[\delta N_{k-1}^{2}\left(t_{k}\right)+\frac{\delta F_{k}}{\alpha_{d}}\left(1-e^{\alpha_{d}\left(t-t_{k}\right)}\right)\right] e^{-\alpha_{d}\left(t-t_{k}\right)}} & {\left[t_{k}, t_{k}+\Delta t_{k}\right)} \\ {\left[\delta N_{k-1}^{2}\left(t_{k}\right)+\frac{\delta F_{k}}{\alpha_{d}}\left(1-e^{\alpha_{d} \Delta t_{k}}\right)\right] e^{\left(\alpha_{a}-\alpha_{d}\right) \Delta t_{k}-\alpha_{a}\left(t-t_{k}\right)}} & {\left[t_{k}+\Delta t_{k}, t_{k}+\Delta \tau_{k}\right)}\end{cases}$

\section{A1.3 $\delta N_{k-1}^{2}$ initial condition}

$\delta N_{k-1}^{2}\left(t_{k}\right)$ is a recursive initial condition, as its initial condition is the event before it, and so on:

$\begin{aligned} \delta N_{k-1}^{2}\left(t_{k}\right) & =\left[\delta N_{k-2}^{2}\left(t_{k-1}\right)+\frac{\delta F_{k-1}}{\alpha_{d}}\left(1-e^{\alpha_{d} \Delta t_{k-1}}\right)\right] e^{\left(\alpha_{a}-\alpha_{d}\right) \Delta t_{k-1}-\alpha_{a} \Delta \tau_{k-1}} \\ \delta N_{k-2}^{2}\left(t_{k-1}\right) & =\left[\delta N_{k-3}^{2}\left(t_{k-2}\right)+\frac{\delta F_{k-2}}{\alpha_{d}}\left(1-e^{\alpha_{d} \Delta t_{k-2}}\right)\right] e^{\left(\alpha_{a}-\alpha_{d}\right) \Delta t_{k-2}-\alpha_{a} \Delta \tau_{k-2}}\end{aligned}$

Therefore, $\delta N_{k-1}^{2}\left(t_{k}\right)$ can be simplified in expression by combining the initial conditions:

$$
\begin{aligned}
\delta N_{k-1}^{2}\left(t_{k}\right) & =\delta N_{k-m}^{2}\left(t_{k-(m-1)}\right) e^{\left(\alpha_{a}-\alpha_{d}\right) \sum_{i=1}^{m-1} \Delta t_{k-i}} e^{-\alpha_{a} \sum_{i=1}^{m-1} \Delta \tau_{k-i}} \\
& +\sum_{j=1}^{m-1} \frac{\delta F_{k_{j}}}{\alpha_{d}}\left(1-e^{\alpha_{d} \Delta t_{k-j}}\right) e^{\left(\alpha_{a}-\alpha_{d}\right) \sum_{i=1}^{j} \Delta t_{k-i}} e^{-\alpha_{a} \sum_{i=1}^{j} \Delta \tau_{k-i}}
\end{aligned}
$$

If $m=k$ and $\delta N_{0}^{2}=0$ :

$\delta N_{k-1}^{2}\left(t_{k}\right)=\sum_{j=1}^{k-1} \frac{\delta F_{k_{j}}}{\alpha_{d}}\left(1-e^{\alpha_{d} \Delta t_{k-j}}\right) e^{\left(\alpha_{a}-\alpha_{d}\right) \sum_{i=1}^{j} \Delta t_{k-i}} e^{-\alpha_{a} \sum_{i=1}^{j} \Delta \tau_{k-i}}$

Assuming $\delta F_{k}=\delta F, \Delta t_{k}=\Delta t$, and $\Delta \tau_{k}=\Delta \tau$ for all $k$, or a periodic pulse function, then $\delta N_{k-1}^{2}$ can be expressed as:

$\delta N_{k-1}^{2}\left(t_{k}\right)=\frac{\delta F}{\alpha_{d}}\left(1-e^{\alpha_{d} \Delta t}\right) \sum_{j=1}^{k-1} e^{\left[\left(\alpha_{a}-\alpha_{d}\right) \Delta t-\alpha_{a} \Delta \tau\right] j}$

Taking the sum of a finite geometric series:

$$
\begin{aligned}
& \sum_{n=0}^{m-1} r^{n}=\left(\frac{1-r^{m}}{1-r}\right) \\
& \sum_{n=0}^{m-1} r^{n}=\sum_{n=1}^{m-1} r^{n}+1 \\
& \sum_{n=1}^{m-1} r^{n}=\sum_{n=0}^{m-1} r^{n}-1
\end{aligned}
$$


https://doi.org/10.5194/os-2021-72

Preprint. Discussion started: 9 August 2021

(c) Author(s) 2021. CC BY 4.0 License.

where $r \neq 1$. If $r=e^{\left(\alpha_{a}-\alpha_{d}\right) \Delta t-\alpha_{a} \Delta \tau}$ :

$\sum_{j=1}^{k-1} e^{\left[\left(\alpha_{a}-\alpha_{d}\right) \Delta t-\alpha_{a} \Delta \tau\right] j}=\left(\frac{1-e^{\left[\left(\alpha_{a}-\alpha_{d}\right) \Delta t-\alpha_{a} \Delta \tau\right] k}}{1-e^{\left[\left(\alpha_{a}-\alpha_{d}\right) \Delta t-\alpha_{a} \Delta \tau\right]}}-1\right)$

$\delta N_{k-1}^{2}\left(t_{k}\right)=\frac{\delta F}{\alpha_{d}}\left(1-e^{\alpha_{d} \Delta t}\right)\left(\frac{1-e^{\left[\left(\alpha_{a}-\alpha_{d}\right) \Delta t-\alpha_{a} \Delta \tau\right] k}}{1-e^{\left[\left(\alpha_{a}-\alpha_{d}\right) \Delta t-\alpha_{a} \Delta \tau\right]}}-1\right)$

where $\left(\alpha_{a}-\alpha_{d}\right) \Delta t-\alpha_{a} \Delta \tau \neq 0$. Plugging Eq. (A32) into Eq. (A22) and (A24) results in the equation for the response of the Brunt-Väisälä frequency forced by a periodic pulse function:

$\delta N^{2}(t)= \begin{cases}\frac{\delta F}{\alpha_{d}}\left[\left(1-e^{\alpha_{d} \Delta t}\right)\left(\frac{1-e^{\left[\left(\alpha_{a}-\alpha_{d}\right) \Delta t-\alpha_{a} \Delta \tau\right] k}}{1-e^{\left[\left(\alpha_{a}-\alpha_{d}\right) \Delta t-\alpha_{a} \Delta \tau\right]}}-1\right)+\left(1-e^{\alpha_{d}\left(t-t_{k}\right)}\right)\right] e^{-\alpha_{d}\left(t-t_{k}\right)} & {\left[t_{k}, t_{k}+\Delta t\right)} \\ \frac{\delta F}{\alpha_{d}}\left[\left(1-e^{\alpha_{d} \Delta t}\right)\left(\frac{1-e^{\left[\left(\alpha_{a}-\alpha_{d}\right) \Delta t-\alpha_{a} \Delta \tau\right] k}}{1-e^{\left[\left(\alpha_{a}-\alpha_{d}\right) \Delta t-\alpha_{a} \Delta \tau\right]}}-1\right)+\left(1-e^{\alpha_{d} \Delta t}\right)\right] e^{\left(\alpha_{a}-\alpha_{d}\right) \Delta t-\alpha_{a}\left(t-t_{k}\right)} & {\left[t_{k}+\Delta t, t_{k}+\Delta \tau\right)}\end{cases}$

For the anomaly response, Eq. (A25) and (A33), assuming a vertically homogeneous $\delta N^{2}$ leads to the stratification index through Eq. (6), leads us to $\delta S I$ being expressed as:

$\delta S I_{k}(t)= \begin{cases}{\left[\delta S I_{k-1}^{2}\left(t_{k}\right)+\frac{D^{2}}{2} \frac{\delta F_{k}}{\alpha_{d}}\left(1-e^{\alpha_{d}\left(t-t_{k}\right)}\right)\right] e^{-\alpha_{d}\left(t-t_{k}\right)}} & {\left[t_{k}, t_{k}+\Delta t_{k}\right)} \\ {\left[\delta S I_{k-1}^{2}\left(t_{k}\right)+\frac{D^{2}}{2} \frac{\delta F_{k}}{\alpha_{d}}\left(1-e^{\alpha_{d} \Delta t_{k}}\right)\right] e^{\left(\alpha_{a}-\alpha_{d}\right) \Delta t_{k}-\alpha_{a}\left(t-t_{k}\right)}} & {\left[t_{k}+\Delta t_{k}, t_{k}+\Delta \tau_{k}\right)}\end{cases}$

And:

$\delta S I_{k}(t)=\left\{\begin{array}{lll}\frac{D^{2}}{2} \frac{\delta F}{\alpha_{d}}\left[\left(1-e^{\alpha_{d} \Delta t}\right)\left(\frac{1-e^{\left[\left(\alpha_{a}-\alpha_{d}\right) \Delta t-\alpha_{a} \Delta \tau\right] k}}{1-e^{\left[\left(\alpha_{a}-\alpha_{d}\right) \Delta t-\alpha_{a} \Delta \tau\right]}}-1\right)+\left(1-e^{\alpha_{d}\left(t-t_{k}\right)}\right)\right] e^{-\alpha_{d}\left(t-t_{k}\right)} & {\left[t_{k}, t_{k}+\Delta t\right)} \\ \frac{D^{2}}{2} \frac{\delta F}{\alpha_{d}}\left[\left(1-e^{\alpha_{d} \Delta t}\right)\left(\frac{1-e^{\left[\left(\alpha_{a}-\alpha_{d}\right) \Delta t-\alpha_{a} \Delta \tau\right] k}}{1-e^{\left[\left(\alpha_{a}-\alpha_{d}\right) \Delta t-\alpha_{a} \Delta \tau\right]}}-1\right)+\left(1-e^{\alpha_{d} \Delta t}\right)\right] e^{\left(\alpha_{a}-\alpha_{d}\right) \Delta t-\alpha_{a}\left(t-t_{k}\right)} & {\left[t_{k}+\Delta t, t_{k}+\Delta \tau\right)}\end{array}\right.$

for the period pulse function case.

\section{A2 Restoring coefficients, $\alpha_{d}$ and $\alpha_{a}$}

The restoration coefficients, $\alpha_{d}$ and $\alpha_{a}$, can be solved for the separate phases of a Mistral event in Eq. (A34) by normalizing the equations during their respective phases. These normalized equations are then fitted to selected, ideal Mistral destratification and restratification cases that are highlighted in Table 1 and Fig. 7 to retrieve the values of the restoration coefficients. 
https://doi.org/10.5194/os-2021-72

Preprint. Discussion started: 9 August 2021

(c) Author(s) 2021. CC BY 4.0 License.

\section{A2.1 Restoration coefficient $\alpha_{d}$, during a Mistral}

To solve for $\alpha_{d}$, we normalize Eq. (A34) for during a Mistral event, $\left[t_{k}, t_{k}+\Delta t_{k}\right.$ ), with $\delta S I$ given as:

$\delta S I_{k}(t)=\left[\delta S I_{k-1}^{2}\left(t_{k}\right)+\frac{D^{2}}{2} \frac{\delta F_{k}}{\alpha_{d}}\left(1-e^{\alpha_{d}\left(t-t_{k}\right)}\right)\right] e^{-\alpha_{d}\left(t-t_{k}\right)}$

We first reference the time, $t$, to the starting time of event $k$ as $t^{\prime}=t-t_{k}$, giving us:

$\delta S I_{k}\left(t^{\prime}\right)=\left[\delta S I_{k-1}^{2}\left(t_{k}\right)+\frac{D^{2}}{2} \frac{\delta F_{k}}{\alpha}\left(1-e^{\alpha_{d} t^{\prime}}\right)\right] e^{-\alpha_{d} t^{\prime}}$

515 Next, we normalize $\delta S I_{k}$ to the value of zero at $t^{\prime}=0$, resulting in $\delta S I_{k, N I}$ :

$$
\begin{aligned}
\delta S I_{k, N I}\left(t^{\prime}\right)=\delta S I_{k}\left(t^{\prime}\right)-\delta S I_{k}\left(t^{\prime}=0\right) & =\left[\delta S I_{k-1}\left(t_{k}\right)+\frac{D^{2}}{2} \frac{\delta F_{k}}{\alpha_{d}}\left(1-e^{\alpha_{d} t^{\prime}}\right)\right] e^{-\alpha_{d} t^{\prime}}-\delta S I_{k-1}\left(t_{k}\right) \\
& =\left[\delta S I_{k-1}\left(t_{k}\right)+\frac{D^{2}}{2} \frac{\delta F_{k}}{\alpha_{d}}\right]\left(e^{-\alpha_{d} t^{\prime}}-1\right)
\end{aligned}
$$

Then the height or magnitude of destratification for each event is normalized to 1 , resulting in $\delta S I_{k, N H}$ :

$\delta S I_{k, N H}\left(t^{\prime}\right)=\frac{\delta S I_{k, N I}\left(t^{\prime}\right)}{\text { extremum }\left(\delta S I_{k, N I}\left(t^{\prime}\right)\right)}$

The extremum value for $\delta S I_{k, N I}\left(t^{\prime}\right)$ is when $t^{\prime}=\Delta t_{k}$, or at the end of the Mistral event. This simplifies $\delta S I_{k, N H}$ to:

$\delta S I_{k, N H}\left(t^{\prime}\right)=\frac{\left[\delta S I_{k-1}\left(t_{k}\right)+\frac{D^{2}}{2} \frac{\delta F_{k}}{\alpha_{d}}\right]\left(e^{-\alpha_{d} t^{\prime}}-1\right)}{\left[\delta S I_{k-1}\left(t_{k}\right)+\frac{D^{2}}{2} \frac{\delta F_{k}}{\alpha_{d}}\right]\left(e^{-\alpha_{d} \Delta t_{k}}-1\right)}=\frac{\left(e^{-\alpha_{d} t^{\prime}}-1\right)}{\left(e^{-\alpha_{d} \Delta t_{k}}-1\right)}$

Then, to normalize the length of the event duration from 0 to 1 , we divide $t^{\prime}$ by the event length, $\Delta t_{k}$, which results in $t^{\prime \prime}$ :

$t^{\prime \prime}=\frac{t^{\prime}}{\Delta t_{k}} \Rightarrow t^{\prime}=t^{\prime \prime} \Delta t_{k}$

Plugging $t^{\prime \prime}$ into $\delta S I_{k, N H}\left(t^{\prime}\right)$ returns $\delta S I_{k, N T}$ :

$\delta S I_{k, N T}\left(t^{\prime \prime}\right)=\frac{e^{-\alpha_{d} t^{\prime \prime} \Delta t_{k}}-1}{e^{-\alpha_{d} \Delta t_{k}}-1}$

This final equation, $\delta S I_{k, N T}$, can be used with a fitting function to solve for $\alpha_{d}$, if $\Delta t_{k}$ is supplied. 
https://doi.org/10.5194/os-2021-72

Preprint. Discussion started: 9 August 2021

(c) Author(s) 2021. CC BY 4.0 License.

\section{A2.2 Restoration coefficient $\alpha_{a}$, after a Mistral}

To solve for $\alpha_{a}$, we normalize Eq. (A34) for after a Mistral event, $\left[t_{k}+\Delta t_{k}, t_{k}+\Delta \tau_{k}\right)$, with $\delta S I$ given as:

$\delta S I_{k}(t)=\left[\delta S I_{k-1}^{2}\left(t_{k}\right)+\frac{D^{2}}{2} \frac{\delta F_{k}}{\alpha_{d}}\left(1-e^{\alpha_{d} \Delta t_{k}}\right)\right] e^{\left(\alpha_{a}-\alpha_{d}\right) \Delta t_{k}-\alpha_{a}\left(t-t_{k}\right)}$

Referencing the time, $t$, to the end of the event, $t^{\prime \prime \prime}=t-\left(t_{k}+\Delta t_{k}\right)$ and plugging $t^{\prime \prime \prime}$ into Eq. (A43), we get:

$\delta S I_{k}\left(t^{\prime \prime \prime}\right)=\left[\delta S I_{k-1}^{2}\left(t_{k}\right)+\frac{D^{2}}{2} \frac{\delta F_{k}}{\alpha_{d}}\left(1-e^{\alpha_{d} \Delta t_{k}}\right)\right] e^{-\alpha_{d} \Delta t_{k}} e^{-\alpha_{a} t^{\prime \prime \prime}}$

Normalizing the vertical intercept of $\delta S I_{k}\left(t^{\prime \prime \prime}\right)$ results in $\delta S I_{k, N I}$ :

$$
\begin{aligned}
\delta S I_{k, N I}=\delta S I_{k}\left(t^{\prime \prime \prime}\right)-\delta S I_{k}\left(t^{\prime \prime \prime}=0\right) & =\left[\delta S I_{k-1}^{2}\left(t_{k}\right)+\frac{D^{2}}{2} \frac{\delta F_{k}}{\alpha_{d}}\left(1-e^{\alpha_{d} \Delta t_{k}}\right)\right] e^{-\alpha_{d} \Delta t_{k}} e^{-\alpha_{a} t^{\prime \prime \prime}} \\
& -\left[\delta S I_{k-1}^{2}\left(t_{k}\right)+\frac{D^{2}}{2} \frac{\delta F_{k}}{\alpha_{d}}\left(1-e^{\alpha_{d} \Delta t_{k}}\right)\right] e^{-\alpha_{d} \Delta t_{k}} \\
& =\left[\delta S I_{k-1}^{2}\left(t_{k}\right)+\frac{D^{2}}{2} \frac{\delta F_{k}}{\alpha_{d}}\left(1-e^{\alpha_{d} \Delta t_{k}}\right)\right] e^{-\alpha_{d} \Delta t_{k}}\left(e^{-\alpha_{a} t^{\prime \prime \prime}}-1\right)
\end{aligned}
$$

Each post event restratification is normalized to the height of 1 by dividing $\delta S I_{k, N I}$ by $\left(\delta S I_{k}\left(t^{\prime \prime \prime}=\Delta \tau_{k}-\Delta t_{k}\right)-\delta S I_{k}\left(t^{\prime \prime \prime}=\right.\right.$ $0))$ :

$$
\begin{aligned}
\delta S I_{k, N H} & =\frac{\delta S I_{k, N I}}{\delta S I_{k}\left(t^{\prime \prime \prime}=\Delta \tau_{k}-\Delta t_{k}\right)-\delta S I_{k}\left(t^{\prime \prime \prime}=0\right)} \\
& =\frac{\left[\delta S I_{k-1}^{2}\left(t_{k}\right)+\frac{D^{2}}{2} \frac{\delta F_{k}}{\alpha_{d}}\left(1-e^{\alpha_{d} \Delta t_{k}}\right)\right] e^{-\alpha_{d} \Delta t_{k}}\left(e^{-\alpha_{a} t^{\prime \prime \prime}}-1\right)}{\left[\delta S I_{k-1}^{2}\left(t_{k}\right)+\frac{D^{2}}{2} \frac{\delta F_{k}}{\alpha_{d}}\left(1-e^{\alpha_{d} \Delta t_{k}}\right)\right] e^{-\alpha_{d} \Delta t_{k}}\left(e^{-\alpha_{a}\left(\Delta \tau_{k}-\Delta t_{k}\right)}-1\right)} \\
& =\frac{e^{-\alpha_{a} t^{\prime \prime \prime}}-1}{e^{-\alpha\left(\Delta \tau_{k}-\Delta t_{k}\right)}-1}
\end{aligned}
$$

which gives us $\delta S I_{k, N H}$.

To normalize the length of time of post event restratification, we will divide $t^{\prime \prime \prime}$ by the post event time length, $\Delta \tau_{k}-\Delta t_{k}$, resulting in $t^{\prime \prime \prime \prime}$ :

$t^{\prime \prime \prime \prime}=\frac{t^{\prime \prime \prime}}{\Delta \tau_{k}-\Delta t_{k}} \Rightarrow t^{\prime \prime \prime}=t^{\prime \prime \prime \prime}\left(\Delta \tau_{k}-\Delta t_{k}\right)$

which leads to $\delta S I_{k, N T}$ :

$\delta S I_{k, N T}=\frac{e^{-\alpha_{a} t^{\prime \prime \prime \prime}\left(\Delta \tau_{k}-\Delta t_{k}\right)}-1}{e^{-\alpha_{a}\left(\Delta \tau_{k}-\Delta t_{k}\right)}-1}$ 
https://doi.org/10.5194/os-2021-72

Preprint. Discussion started: 9 August 2021

(c) Author(s) 2021. CC BY 4.0 License.

Table A1. The Mistral strengths, $\delta F_{k}$, for each of the preconditioning phase events, using $\alpha_{d}$ and $\alpha_{a}$ from Sec. A2, and the rest of the preconditioning period Mistral characteristics from Table 1, plugged into Eq. (A50).

\begin{tabular}{lr|lr}
\hline Date & $\delta F_{k} s^{-2} d a y^{-1} \times 10^{-8}$ & Date & $\delta F_{k} s^{-2} d a y^{-1} \times 10^{-8}$ \\
\hline $2012-08-30$ & 1.81 & $2012-11-19$ & 3.92 \\
$2012-09-12$ & 2.67 & $2012-11-27$ & 5.46 \\
$2012-09-19$ & 2.66 & $2012-12-08$ & 6.37 \\
$2012-09-28$ & 2.73 & $2012-12-17$ & 5.30 \\
$2012-10-12$ & 3.04 & $2012-12-21$ & 5.03 \\
$2012-10-27$ & 4.59 & $2012-12-26$ & 4.39 \\
$2012-11-11$ & 4.84 & $2013-01-02$ & 3.80 \\
$2012-11-19$ & 3.92 & $2013-01-23$ & 3.53 \\
\hline$\overline{\delta F_{k}}=4.01 \times 10^{-8} s^{-2} d a y^{-1}$ and $\sigma_{\delta F_{k}}=1.196 \times 10^{-8} s^{-2}$ day $^{-1}$
\end{tabular}

This leaves us with an equation of $\alpha_{a}$, which can be fitted against NEMO model data, if $\Delta t_{k}$ and $\Delta \tau_{k}$ are provided.

The average duration and period, $\overline{\Delta t}$ and $\overline{\Delta \tau}$, of events during the preconditioning period in Table 1 are used for $\Delta t$ and $\Delta \tau$ in these normalized equations, Eq. (A42) and (A48). The result of the fitting is shown in Fig. 10, with $\alpha_{d}$ having a fitted valued of $0.235 d a y^{-1}$ and $\alpha_{a}$ having a fitted value of $0.021 \mathrm{day}^{-1}$.

\section{A3 Determining $\delta F_{k}$}

With the restoring coefficients determined in the prior section, Sec. A2, and the duration and period of each event available in Table 1, the strength of each Mistral event, $\delta F_{k}$, can be determined. If we take Eq. (A36) and note the value of $\delta S I_{k-1}$ to be the same as $\delta S I_{k}\left(t_{k}\right)$ at the beginning of an event, we can simplify the equation in the following steps:

550

$$
\delta S I_{k}\left(t_{k}\right)=\delta S I_{k-1}
$$

$\delta S I_{k}\left(t_{k}+\Delta t_{k}\right)=\delta S I_{k-1} e^{-\alpha_{d} \Delta t_{k}}+\frac{D^{2}}{2} \frac{\delta F_{k}}{\alpha_{d}}\left(e^{-\alpha_{d} \Delta t_{k}}-1\right)$

And then solve for $\delta F_{k}$ :

$\delta F_{k}=\frac{2\left(\delta S I_{k}\left(t_{k}+\Delta t_{k}\right)-\delta S I_{k}\left(t_{k}\right) e^{-\alpha_{d} \Delta t_{k}}\right) \alpha_{d}}{\left(e^{-\alpha_{d} \Delta t_{k}}-1\right) D^{2}}$

The results of $\delta F_{k}$ for each event in the preconditioning phase is given in Table A1, along with mean and standard deviation.

\section{A4 Time derivative of $\delta N^{2}$}

555 Taking the derivative with respect to time of Eq. (A25) and (A34) results in: 
https://doi.org/10.5194/os-2021-72

Preprint. Discussion started: 9 August 2021

(c) Author(s) 2021. CC BY 4.0 License.

$\frac{\partial \delta N_{k}^{2}(t)}{\partial t}= \begin{cases}-\alpha_{d}\left[\delta N_{k-1}^{2}\left(t_{k}\right)+\frac{\delta F_{k}}{\alpha_{d}}\right] e^{-\alpha_{d}\left(t-t_{k}\right)} & {\left[t_{k}, t_{k}+\Delta t_{k}\right)} \\ -\alpha_{a}\left[\delta N_{k-1}^{2}\left(t_{k}\right)+\frac{\delta F_{k}}{\alpha_{d}}\left(1-e^{\alpha_{d} \Delta t_{k}}\right)\right] e^{\left(\alpha_{a}-\alpha_{d}\right) \Delta t_{k}-\alpha_{a}\left(t-t_{k}\right)} & {\left[t_{k}+\Delta t_{k}, t_{k}+\Delta \tau_{k}\right)}\end{cases}$

and:

$\frac{\partial \delta S I_{k}(t)}{\partial t}= \begin{cases}-\alpha_{d}\left[\delta S I_{k-1}\left(t_{k}\right)+\frac{D^{2}}{2} \frac{\delta F_{k}}{\alpha_{d}}\right] e^{-\alpha_{d}\left(t-t_{k}\right)} & {\left[t_{k}, t_{k}+\Delta t_{k}\right)} \\ -\alpha_{a}\left[\delta S I_{k-1}\left(t_{k}\right)+\frac{D^{2}}{2} \frac{\delta F_{k}}{\alpha_{d}}\left(1-e^{\alpha_{d} \Delta t_{k}}\right)\right] e^{\left(\alpha_{a}-\alpha_{d}\right) \Delta t_{k}-\alpha_{a}\left(t-t_{k}\right)} & {\left[t_{k}+\Delta t_{k}, t_{k}+\Delta \tau_{k}\right)}\end{cases}$

\section{A5 Asymptotic destratification}

560 The following sections under Sec. A5 differentiate Eq. (A35) at $t=t_{k}+\Delta t_{k}$, or at the end of a Mistral event, where the destratification is the largest, by $k$, and by the other components, $\delta F, \Delta t$, and $\Delta \tau$, once $k \rightarrow \infty$.

\section{A5.1 $\frac{\partial \delta S I_{k}}{\partial k}$}

Equation (A35), at $t=t_{k}+\Delta t$ results in:

$\delta S I_{k}\left(t_{k}+\Delta t\right)=\frac{D^{2}}{2} \frac{\delta F}{\alpha_{d}}\left(e^{-\alpha_{d} \Delta t}-1\right)\left(\frac{1-e^{\left[\left(\alpha_{a}-\alpha_{d}\right) \Delta t-\alpha_{a} \Delta \tau\right] k}}{1-e^{\left(\alpha_{a}-\alpha_{d}\right) \Delta t-\alpha_{a} \Delta \tau}}\right)$

565 The derivative of Eq. (A53) with respect to (w.r.t.) $k$ is:

$\frac{\partial \delta S I_{k}}{\partial k}=\frac{D^{2}}{2} \frac{\delta F}{\alpha_{d}} \frac{\left(e^{-\alpha_{d} \Delta t}-1\right)}{\left(1-e^{\left(\alpha_{a}-\alpha_{d}\right) \Delta t-\alpha_{a} \Delta \tau}\right)}\left(-e^{\left[\left(\alpha_{a}-\alpha_{d}\right) \Delta t-\alpha_{a} \Delta \tau\right] k}\right)\left[\left(\alpha_{a}-\alpha_{d}\right) \Delta t-\alpha_{a} \Delta \tau\right]$

As $k \rightarrow \infty$, with $\alpha_{d}>\alpha_{a}$, Eq. (A53) goes to:

$\delta S I_{\infty}=\frac{D^{2}}{2} \frac{\delta F}{\alpha_{d}}\left(e^{-\alpha_{d} \Delta t}-1\right)\left(\frac{1}{1-e^{\left(\alpha_{a}-\alpha_{d}\right) \Delta t-\alpha_{a} \Delta \tau}}\right)$

\section{A5.2 $\frac{\partial \delta S I_{\infty}}{\partial \delta F}$}

570 The derivative of Eq. (A55) w.r.t. $\delta F$ is:

$\frac{\partial \delta S I_{\infty}}{\partial \delta F}=\frac{D^{2}}{2} \frac{1}{\alpha_{d}}\left(e^{-\alpha_{d} \Delta t}-1\right)\left(\frac{1}{1-e^{\left(\alpha_{a}-\alpha_{d}\right) \Delta t-\alpha_{a} \Delta \tau}}\right)$ 
https://doi.org/10.5194/os-2021-72

Preprint. Discussion started: 9 August 2021

(c) Author(s) 2021. CC BY 4.0 License.

\section{$\mathbf{A 5 . 3} \frac{\partial \delta S I_{\infty}}{\partial \Delta t}$}

The derivative of Eq. (A55) w.r.t. $\Delta t$ is:

$\frac{\partial \delta S I_{\infty}}{\partial \Delta t}=\frac{D^{2}}{2} \frac{\delta F}{\alpha_{d}} \frac{1}{\left(1-e^{\left(\alpha_{a}-\alpha_{d}\right) \Delta t-\alpha_{a} \Delta \tau}\right)}\left[-\alpha_{d} e^{-\alpha_{d} \Delta t}+\left(e^{-\alpha_{d} \Delta t}-1\right)\left(\frac{\left(\alpha_{a}-\alpha_{d}\right) e^{\left(\alpha_{a}-\alpha_{d}\right) \Delta-\alpha_{a} \Delta \tau}}{1-e^{\left(\alpha_{a}-\alpha_{d}\right) \Delta t-\alpha_{a} \Delta \tau}}\right)\right]$

$575 \quad \mathbf{A 5 . 4} \quad \frac{\partial \delta S I_{\infty}}{\partial \Delta \tau}$

The derivative of Eq. (A55) w.r.t. $\Delta \tau$ is:

$$
\frac{\partial \delta S I_{\infty}}{\partial \Delta \tau}=\frac{D^{2}}{2} \frac{\delta F}{\alpha_{d}}\left(e^{-\alpha_{d} \Delta t}-1\right) \frac{\left(-\alpha_{a} e^{\left(\alpha_{a}-\alpha_{d}\right) \Delta t-\alpha_{a} \Delta \tau}\right)}{\left(1-e^{\left(\alpha_{a}-\alpha_{d}\right) \Delta t-\alpha_{a} \Delta \tau}\right)^{2}}
$$

Author contributions. Douglas Keller Jr. performed the majority of the analysis presented. Yonatan Givon provided analysis with respect to Mistral events. Romain Pennel provided assistance and guidance running the ocean simulations. Shira Raveh-Rubin and Philippe Drobinski provided analytical assistance and guidance.

Competing interests. The authors declare there are no conflicting interests.

Acknowledgements. This work is a contribution to the HyMeX program (HYdrological cycle in the Mediterranean EXperiment) through INSU-MISTRALS support and the Med-CORDEX program (COordinated Regional climate Downscaling EXperiment - Mediterranean region). It was also supported by a joint CNRS - Weizmann Institute of Science collaborative project. The authors acknowledge MétéoFrance for supplying the data and the HyMeX database teams (ESPRI/IPSL and SEDOO/Observatoire Midi-Pyrénées) for their help in accessing the data. 
https://doi.org/10.5194/os-2021-72

Preprint. Discussion started: 9 August 2021

\section{References}

Arsouze, T., Beuvier, J., Béranger, K., Bourdallé-Badie, R., Deltel, C., Drillet, Y., Drobinski, P., Ferry, N., Lebeaupin-Brossier, C., Lyard, F., Sevault, F., and Somot, S.: Release note of the high-resolution oceanic model in the Mediterranean Sea NEMO-MED12 based on NEMO 3.2 version, Tech. rep., Centre National de Recherches Météorologiques.

Balmaseda, M. A., Trenberth, K. E., and Källén, E.: Distinctive climate signals in reanalysis of global ocean heat content, Geophysical Research Letters, 40, 1754-1759, https://doi.org/10.1002/grl.50382, 2013.

Beuvier, J., Béranger, K., Brossier, C. L., Somot, S., Sevault, F., Drillet, Y., Bourdallé-Badie, R., Ferry, N., and Lyard, F.: Spreading of the Western Mediterranean Deep Water after winter 2005: Time scales and deep cyclone transport, Journal of Geophysical Research: Oceans, 117, n/a-n/a, https://doi.org/10.1029/2011jc007679, 2012.

Béranger, K., Testor, P., and Crépon, M.: Modelling water mass formation in the Gulf of Lions (Mediterranean Sea), CIESM Workshop Monographs, 2009.

Coppola, L., Prieur, L., Taupier-Letage, I., Estournel, C., Testor, P., Lefevre, D., Belamari, S., LeReste, S., and Taillandier, V.: Observation of oxygen ventilation into deep waters through targeted deployment of multiple Argo-O2floats in the north-western Mediterranean Sea in 2013, Journal of Geophysical Research: Oceans, 122, 6325-6341, https://doi.org/10.1002/2016jc012594, 2017.

Dee, D. P., Uppala, S. M., Simmons, A. J., Berrisford, P., Poli, P., Kobayashi, S., Andrae, U., Balmaseda, M. A., Balsamo, G., Bauer, P., Bechtold, P., Beljaars, A. C. M., van de Berg, L., Bidlot, J., Bormann, N., Delsol, C., Dragani, R., Fuentes, M., Geer, A. J., Haimberger, L., Healy, S. B., Hersbach, H., Hólm, E. V., Isaksen, L., Kållberg, P., Köhler, M., Matricardi, M., McNally, A. P., Monge-Sanz, B. M., Morcrette, J.-J., Park, B.-K., Peubey, C., de Rosnay, P., Tavolato, C., Thépaut, J.-N., and Vitart, F.: The ERA-Interim reanalysis: configuration and performance of the data assimilation system, Quarterly Journal of the Royal Meteorological Society, 137, 553-597, https://doi.org/10.1002/qj.828, 2011.

Drobinski, P., Ducrocq, V., Alpert, P., Anagnostou, E., Béranger, K., Borga, M., Braud, I., Chanzy, A., Davolio, S., Delrieu, G., Estournel, C., Boubrahmi, N. F., Font, J., Grubišić, V., Gualdi, S., Homar, V., Ivančan-Picek, B., Kottmeier, C., Kotroni, V., Lagouvardos, K., Lionello, P., Llasat, M. C., Ludwig, W., Lutoff, C., Mariotti, A., Richard, E., Romero, R., Rotunno, R., Roussot, O., Ruin, I., Somot, S., TaupierLetage, I., Tintore, J., Uijlenhoet, R., and Wernli, H.: HyMeX: A 10-Year Multidisciplinary Program on the Mediterranean Water Cycle, Bulletin of the American Meteorological Society, 95, 1063-1082, https://doi.org/10.1175/bams-d-12-00242.1, 2014.

Drobinski, P., Alonzo, B., Basdevant, C., Cocquerez, P., Doerenbecher, A., Fourrié, N., and Nuret, M.: Lagrangian dynamics of the mistral during the HyMeX SOP2, Journal of Geophysical Research: Atmospheres, 122, 1387-1402, https://doi.org/10.1002/2016jd025530, 2017.

Estournel, C., , Testor, P., Taupier-Letage, I., Bouin, M.-N., Coppola, L., Durand, P., Conan, P., Bosse, A., Brilouet, P.-E., Beguery, L., Belamari, S., Béranger, K., Beuvier, J., Bourras, D., Canut, G., Doerenbecher, A., de Madron, X. D., D’Ortenzio, F., Drobinski, P., Ducrocq, V., Fourrié, N., Giordani, H., Houpert, L., Labatut, L., Brossier, C. L., Nuret, M., Prieur, L., Roussot, O., Seyfried, L., and Somot, S.: HyMeX-SOP2: The Field Campaign Dedicated to Dense Water Formation in the Northwestern Mediterranean, Oceanography, 29, 196-206, https://doi.org/10.5670/oceanog.2016.94, 2016a.

Estournel, C., Testor, P., Damien, P., D'Ortenzio, F., Marsaleix, P., Conan, P., Kessouri, F., de Madron, X. D., Coppola, L., Lellouche, J.-M., Belamari, S., Mortier, L., Ulses, C., Bouin, M.-N., and Prieur, L.: High resolution modeling of dense water formation in the northwestern Mediterranean during winter 2012-2013: Processes and budget, Journal of Geophysical Research: Oceans, 121, 5367-5392, https://doi.org/10.1002/2016jc011935, 2016b. 
https://doi.org/10.5194/os-2021-72

Preprint. Discussion started: 9 August 2021

Flamant, C.: Alpine lee cyclogenesis influence on air-sea heat exchanges and marine atmospheric boundary layer thermodynamics over the western Mediterranean during a Tramontane/Mistral event, Journal of Geophysical Research: Oceans, 108, n/a-n/a, https://doi.org/10.1029/2001jc001040, 2003.

Gascard, J. C.: Mediterranean deep water formation baroclinic instability and oceanic eddies, Oceanologica Acta, 1978.

Givon, Y., Jr., D. K., Pennel, R., Drobinski, P., and Raveh-Rubin, S.: Synoptic-scale drivers of the Mistral wind: link to Rossby wave life cycles and seasonal variability, https://doi.org/10.5194/wcd-2021-7, accepted, 2021.

Group, T. L. S.: The Labrador Sea Deep Convection Experiment, Bulletin of the American Meteorological Society, 79, 2033-2058, https://doi.org/10.1175/1520-0477(1998)079<2033:tlsdce>2.0.co;2, 1998.

Guion, A., Turquety, S., Polcher, J., Pennel, R., Bastin, S., and Arsouze, T.: Droughts and heatwaves in the Western Mediterranean: impact on vegetation and wildfires using the coupled WRF-ORCHIDEE regional model (RegIPSL), Climate Dynamics, in review, 2021.

Hamon, M., Beuvier, J., Somot, S., Lellouche, J.-M., Greiner, E., Jordà, G., Bouin, M.-N., Arsouze, T., Béranger, K., Sevault, F., Dubois, C., Drevillon, M., and Drillet, Y.: Design and validation of MEDRYS, a Mediterranean Sea reanalysis over the period 1992-2013, Ocean Science, 12, 577-599, https://doi.org/10.5194/os-12-577-2016, 2016.

Herrmann, M., Sevault, F., Beuvier, J., and Somot, S.: What induced the exceptional 2005 convection event in the northwestern Mediterranean basin? Answers from a modeling study, Journal of Geophysical Research, 115, https://doi.org/10.1029/2010jc006162, 2010.

Houpert, L., de Madron, X. D., Testor, P., Bosse, A., D'Ortenzio, F., Bouin, M. N., Dausse, D., Goff, H. L., Kunesch, S., Labaste, M., Coppola, L., Mortier, L., and Raimbault, P.: Observations of open-ocean deep convection in the northwestern Mediterranean Sea: Seasonal and interannual variability of mixing and deep water masses for the 2007-2013 Period, Journal of Geophysical Research: Oceans, 121, 8139-8171, https://doi.org/10.1002/2016jc011857, 2016.

Krinner, G., Viovy, N., de Noblet-Ducoudré, N., Ogée, J., Polcher, J., Friedlingstein, P., Ciais, P., Sitch, S., and Prentice, I. C.: A dynamic global vegetation model for studies of the coupled atmosphere-biosphere system, Global Biogeochemical Cycles, 19, https://doi.org/10.1029/2003gb002199, 2005.

Large, W. and Yeager, S.: Diurnal to decadal global forcing for ocean and sea-ice models: The data sets and flux climatologies, Tech. rep., https://doi.org/10.5065/D6KK98Q6, 2004.

Large, W. G. and Yeager, S. G.: The global climatology of an interannually varying air-sea flux data set, Climate Dynamics, 33, 341-364, https://doi.org/10.1007/s00382-008-0441-3, 2008.

Lebeaupin-Brossier, C. and Drobinski, P.: Numerical high-resolution air-sea coupling over the Gulf of Lions during two tramontane/mistral events, Journal of Geophysical Research, 114, https://doi.org/10.1029/2008jd011601, 2009.

Lebeaupin-Brossier, C., Béranger, K., Deltel, C., and Drobinski, P.: The Mediterranean response to different space-time resolution atmospheric forcings using perpetual mode sensitivity simulations, Ocean Modelling, 36, 1-25, https://doi.org/10.1016/j.ocemod.2010.10.008, 2011.

Lebeaupin-Brossier, C., Béranger, K., and Drobinski, P.: Sensitivity of the northwestern Mediterranean Sea coastal and thermohaline circulations simulated by the $1 / 12^{\circ}$-resolution ocean model NEMO-MED12 to the spatial and temporal resolution of atmospheric forcing, Ocean Modelling, 43-44, 94-107, https://doi.org/10.1016/j.ocemod.2011.12.007, 2012.

Lebeaupin-Brossier, C., Léger, F., Giordani, H., Beuvier, J., Bouin, M.-N., Ducrocq, V., and Fourrié, N.: Dense water formation in the north-western M editerranean area during HyMeX-SOP2 in $1 / 36^{\circ}$ ocean simulations: Ocean-atmosphere coupling impact, Journal of Geophysical Research: Oceans, 122, 5749-5773, https://doi.org/10.1002/2016jc012526, 2017. 
https://doi.org/10.5194/os-2021-72

Preprint. Discussion started: 9 August 2021

Léger, F., Brossier, C. L., Giordani, H., Arsouze, T., Beuvier, J., Bouin, M.-N., Bresson, É., Ducrocq, V., Fourrié, N., and Nuret, M.: Dense water formation in the north-western Mediterranean area during HyMeX-SOP2 in $1 / 36^{\circ}$ ocean simulations: Sensitivity to initial conditions, Journal of Geophysical Research: Oceans, 121, 5549-5569, https://doi.org/10.1002/2015jc011542, 2016.

L'Hévéder, B., Li, L., Sevault, F., and Somot, S.: Interannual variability of deep convection in the Northwestern Mediterranean simulated with a coupled AORCM, Climate Dynamics, 41, 937-960, https://doi.org/10.1007/s00382-012-1527-5, 2012.

Ludwig, W., Dumont, E., Meybeck, M., and Heussner, S.: River discharges of water and nutrients to the Mediterranean and Black Sea: Major drivers for ecosystem changes during past and future decades?, Progress in Oceanography, 80, 199-217, https://doi.org/10.1016/j.pocean.2009.02.001, 2009.

Madec, G., Chartier, M., and Crépon, M.: The effect of thermohaline forcing variability on deep water formation in the western Mediterranean Sea: a high-resolution three-dimensional numerical study, Dynamics of Atmospheres and Oceans, 15, 301-332, https://doi.org/10.1016/0377-0265(91)90024-a, 1991a.

Madec, G., Delecluse, P., Crepon, M., and Chartier, M.: A Three-Dimensional Numerical Study of Deep-Water Formation in the Northwestern Mediterranean Sea, Journal of Physical Oceanography, 21, 1349-1371, https://doi.org/10.1175/15200485(1991)021<1349:atdnso>2.0.co;2, 1991b

Madec, G., Lott, F., Delecluse, P., and Crépon, M.: Large-Scale Preconditioning of Deep-Water Formation in the Northwestern Mediterranean Sea, Journal of Physical Oceanography, 26, 1996.

Marshall, J. and Schott, F.: Open-ocean convection: Observations, theory, and models, Reviews of Geophysics, 37, 1-64, https://doi.org/10.1029/98rg02739, 1999.

MEDOC: Observation of Formation of Deep Water in the Mediterranean Sea, 1969, Nature, 227, 1970.

Mertens, C. and Schott, F.: Interannual Variability of Deep-Water Formation in the Northwestern Mediterranean, Journal of Physical Oceanography, 28, 1410-1424, https://doi.org/10.1175/1520-0485(1998)028<1410:ivodwf>2.0.co;2, 1998.

Millot, C. and Taupier-Letage, I.: Circulation in the Mediterranean Sea, in: The Mediterranean Sea, pp. 29-66, Springer Berlin Heidelberg, https://doi.org/10.1007/b107143, 2005.

Noh, Y., Cheon, W. G., and Raasch, S.: The Role of Preconditioning in the Evolution of Open-Ocean Deep Convection, Journal of Physical Oceanography, 33, 1145-1166, https://doi.org/10.1175/1520-0485(2003)033<1145:tropit>2.0.co;2, 2003.

Robinson, A., Leslie, W., Theocharis, A., and Lascaratos, A.: Mediterranean Sea Circulation, in: Encyclopedia of Ocean Sciences, pp. 1689-1705, Elsevier, https://doi.org/10.1006/rwos.2001.0376, 2001.

Ruti, P. M., Somot, S., Giorgi, F., Dubois, C., Flaounas, E., Obermann, A., Dell'Aquila, A., Pisacane, G., Harzallah, A., Lombardi, E., Ahrens, B., Akhtar, N., Alias, A., Arsouze, T., Aznar, R., Bastin, S., Bartholy, J., Béranger, K., Beuvier, J., Bouffies-Cloché, S., Brauch, J., Cabos, W., Calmanti, S., Calvet, J.-C., Carillo, A., Conte, D., Coppola, E., Djurdjevic, V., Drobinski, P., Elizalde-Arellano, A., Gaertner, M., Galàn, P., Gallardo, C., Gualdi, S., Goncalves, M., Jorba, O., Jordà, G., L’Heveder, B., Lebeaupin-Brossier, C., Li, L., Liguori, G., Lionello, P., Maciàs, D., Nabat, P., Önol, B., Raikovic, B., Ramage, K., Sevault, F., Sannino, G., Struglia, M. V., Sanna, A., Torma, C., and Vervatis, V.: Med-CORDEX Initiative for Mediterranean Climate Studies, Bulletin of the American Meteorological Society, 97, 1187-1208, https://doi.org/10.1175/bams-d-14-00176.1, 2016.

Schott, F., Visbeck, M., Send, U., Fischer, J., Stramma, L., and Desaubies, Y.: Observations of Deep Convection in the Gulf of Lions, Northern Mediterranean, during the Winter of 1991/92, Journal of Physical Oceanography, 26, 505-524, https://doi.org/10.1175/15200485(1996)026<0505:oodcit>2.0.co;2, 1996. 
https://doi.org/10.5194/os-2021-72

Preprint. Discussion started: 9 August 2021

(c) Author(s) 2021. CC BY 4.0 License.

(c) (i)

Send, U. and Testor, P.: Direct Observations Reveal the Deep Circulation of the Western Mediterranean Sea, Journal of Geophysical Research:

Oceans, 122, 10 091-10098, https://doi.org/10.1002/2016jc012679, 2017.

Severin, T., Kessouri, F., Rembauville, M., Sánchez-Pérez, E. D., Oriol, L., Caparros, J., Pujo-Pay, M., Ghiglione, J.-F., D'Ortenzio, F.,

Taillandier, V., Mayot, N., Madron, X. D. D., Ulses, C., Estournel, C., and Conan, P.: Open-ocean convection process: A driver of the winter nutrient supply and the spring phytoplankton distribution in the Northwestern Mediterranean Sea, Journal of Geophysical Research:

Oceans, 122, 4587-4601, https://doi.org/10.1002/2016jc012664, 2017.

Skamarock, W., Klemp, J., Dudhia, J., Gill, D., Barker, D., Wang, W., Huang, X.-Y., and Duda, M.: A Description of the Advanced Research WRF Version 3, Tech. rep., https://doi.org/10.5065/D68S4MVH, 2008.

Somot, S.: Modélisation Climatique du Bassin Méditerranéen : Variabilité et Scénarios de Changement Climatique, phdthesis, Université Toulouse III, 2005.

Somot, S., Houpert, L., Sevault, F., Testor, P., Bosse, A., Taupier-Letage, I., Bouin, M.-N., Waldman, R., Cassou, C., Sanchez-Gomez, E., de Madron, X. D., Adloff, F., Nabat, P., and Herrmann, M.: Characterizing, modelling and understanding the climate variability of the deep water formation in the North-Western Mediterranean Sea, Climate Dynamics, 51, 1179-1210, https://doi.org/10.1007/s00382-016-3295-0,

7102016.

Song, X. and Yu, L.: Air-sea heat flux climatologies in the Mediterranean Sea: Surface energy balance and its consistency with ocean heat storage, Journal of Geophysical Research: Oceans, 122, 4068-4087, https://doi.org/10.1002/2016jc012254, 2017.

Taupier-Letage Isabelle: CTD SOP2, Provence - Tethys 2, https://doi.org/10.6096/MISTRALS-HYMEX.950, 2013.

Testor, P. and Gascard, J.-C.: Large-Scale Spreading of Deep Waters in the Western Mediterranean Sea by Submesoscale Coherent Eddies, Journal of Physical Oceanography, 33, 75-87, https://doi.org/10.1175/1520-0485(2003)033<0075:1ssodw>2.0.co;2, 2003.

Turner, J. S.: Buoyancy Effects in Fluids, Cambridge University Press, 1973.

Waldman, R., Brüggemann, N., Bosse, A., Spall, M., Somot, S., and Sevault, F.: Overturning the Mediterranean Thermohaline Circulation, Geophysical Research Letters, 45, 8407-8415, https://doi.org/10.1029/2018g1078502, 2018.

White, F.: Viscous fluid flow, McGraw-Hill Higher Education, New York, NY, 2011. 